\title{
Design Science Research Championing Personal Knowledge Management System Development
}

\author{
Ulrich Schmitt \\ University of Stellenbosch Business School, South Africa
}

\section{schmitt@knowcations.org}

\begin{abstract}
Knowledge Management (KM) is governed by an ill-structured mishmash of complementing as well as conflicting interdisciplinary methodologies and based on physical and social technologies, which too often struggle to achieve their stakeholders' objectives due to diverse scholarly contributions, repetitive polemic discourses, and misguided organizational KM system generations.
\end{abstract}

A novel Personal Knowledge Management (PKM) Concept and Prototype System currently under development take a fresh look and aim to support individuals' academic and professional growth as well as their roles as contributors and beneficiaries of institutional and societal performance. A PKM System (PKMS), hence, is meant to aid life-long-learning, resourcefulness, creativity, and teamwork of knowledge workers. Such a scope offers appealing and viable opportunities for stakeholders in the educational, professional, and developmental context. A recent article employed the systems thinking techniques of the transdiscipline of Informing Science (IS) to align and validate the more specific models and methodologies central to the PKMS concept. In line with the interdisciplinary nature of the concept, further conference papers and journal articles have been disseminated and received feedback from a wide range of disciplines.

This follow-up article turns to the creative process at the heart of the concept and application introduced in the prior publications. Similar to the IS-benchmarking approach, the design thinking is validated against accepted general design science research guidelines. These guidelines are meant to supplement the reactive behavioral (natural) science paradigm with the proactive design science paradigm in order to support information technology (IT) researchers in creating innovative IT artefacts that extend human and social capabilities and meet desired outcomes. Rather than to justify the research paradigm of the PKMS project in an ad hoc and fragmented manner with each new paper, the objective is a dedicated article which presents the design science research perspectives comprehensively as evidence of their relevance, utility, rigor, and publishability in Information Systems research outlets. The URL links to all prior publications facilitate a kind of 'Long Discussion Case' to potentially assist IT researchers and entrepreneurs engaged in

Material published as part of this publication, either on-line or in print, is copyrighted by the Informing Science Institute. Permission to make digital or paper copy of part or all of these works for personal or classroom use is granted without fee provided that the copies are not made or distributed for profit or commercial advantage AND that copies 1) bear this notice in full and 2) give the full citation on the first page. It is permissible to abstract these works so long as credit is given. To copy in all other cases or to republish or to post on a server or to redistribute to lists requires specific permission and payment of a fee. Contact Publisher@InformingScience.org to request redistribution permission. similar projects.

Keywords: Personal Knowledge Management (PKM), Design Science Research (DSR), Informing Science (IS), Popper's Three Worlds, Knowledge Worker, Organizational Knowledge Management (OKM), Human Capital, Capacity Development, Lifelong learning, Memes, Memex, Knowcations. 


\section{PKM as an Individualized Tool for Knowledge Workers}

Initially confined to the author's own Knowledge Management (KM) requirements, an idea formed for a personalized KM system which has been subsequently adapted and continuously expanded for the personal career support as a management consultant, scholar, professor, and academic manager.

The experiences gained with the many stakeholders in the professional and academic world as well as in the context of developed and developing countries have reinforced the conviction that Personal Knowledge Management support is becoming ever more vital, a view shared by many other writers as discussed in prior papers (Schmitt, 2013f, 2014c) and as highlighted by some of the most prominent of these contributions:

- Seven decades ago, Vannevar Bush (1945) imagined the 'Memex'. As an inspiring idea never realized celebrating its $70^{\text {th }}$ anniversary, the 'Memex' represents the as-close-as-itgets ancestor of the PKM concept and system proposed.

- Although progress only recently triggered the change from information scarcity to a never before experienced ever-increasing information abundance, the need for managing the scarce personal attention of those receiving it has been stressed by Simon (1971) already over four decades ago.

- In advancing his groundbreaking SECI-Model, Nonaka $(1995,2000)$ introduced the concept of 'ba' as a shared context or place (physical or virtual) and emphasized the importance of personal knowledge-related proficiencies, individual knowledge assets, personal autonomy, trust and commitment.

- For Wiig (2011), the PKM objective is the desire to make citizens highly knowledgeable to function competently and effectively in their daily lives, as part of the workforce and, as public citizens.

- For Levy (2011), the sustainable growth of autonomous capacities in PKM will be one of the most important future functions of teaching and higher education. He also envisages Knowledge Management experiencing a decentralizing revolution that gives more power and autonomy to individuals and self-organized groups. His scenario is based on decentralized autonomous PKM capacities, networked in continuous feedback loops to enable creative user conversations. Hence, PKM Systems (PKMS) are expected to facilitate the emergence of distributed processes of collective intelligence, which in turn feed them.

However, only current advances in development, hosting, and database platforms have provided a viable opportunity for further advancing the PKM prototype system and converting it into an application serving a wider audience across technological environments.

In parallel to this ongoing software development, further studies of the relevant fields and the publishing of a series of posters, papers, and articles (Schmitt, 2012, 2013a-g, 2014a-n, 2015a-k) have taken place, adding to the insight that the potential benefits justify a far more holistic approach by also encompassing the educational and developmental needs of the emerging knowledge societies. Since these published resources are accessible by using the cited URL and DOI links, this article shifts from a scenario of how Personal KM devices support individuals' academic and professional growth towards an account of how this novel concept and system has been devised.

The aim of this article is thus to retrospectively focus on the design thinking approach taken in the light of recognized design science research frameworks in Information Systems. The outcome adds a novel perspective by sharing the design thinking methodologies adopted to structure the underlying rational and creative processes of the PKM system development project. Part of the article incorporates an unpublished presentation contributing to the Design Thinking Workshop at the 2015 UCT ETILAB conference (Schmitt, 2015j). 


\section{PKM as a Collaborative Tool for Knowledge Workers}

On the one hand, the novel PKM approach benefits the personal, educational, and professional spheres of individual learning and working environments by deviating from the traditional Organizational KM (OKM) systems in four major ways:

- Its Personal Focus ensures one's digitalized knowledge is always at one's disposal and can easily be retrieved, expanded, shared, and re-used independent of changing one's social, educational, professional, or technological environment (Schmitt, 2012, 2014d, 2014f).

- Its Bottom-up Focus entails a departure from today's centralized, top-down, institutional KM developments. However, common knowledge-related methods, resources, and objectives provide strong arguments to exploit synergies between PKM and OKM systems for mutual benefit (Schmitt, 2014h, 2015b, 2015f, 2016d).

- Its Meme Focus, probably the most radical departure from the current document-centric $\mathrm{KM}$ systems, attends to the capturing, storing, and re-purposing of basic information structures (memes or ideas) and their relationships (to create knowledge assets and documents) rather than storing and referencing them the conventional way in their containers only (e.g. book, paper, report) (Schmitt, 20141, 2014j, 2015e, 2015g, 2016a).

- Its Creative Conversation Focus is based on the shared aggregated meme trajectories between PKM system users and provides a multitude of enhanced options to engage in one's topics of interest. Also, collaboratively interlinking knowledge bases to collectively trace, harvest and utilize accumulated knowledge subsets will overall reduce redundant content and improve productivity of information seekers and suppliers alike. Thus, the mission of a proposed 'World Heritage of Memes Repository (WHOMER)' is to guarantee continued access to the collective knowledge and ideas voluntarily shared among the PKMS user community as well as to overcome the redundancy, the perishability, and potential fallibility of current online knowledge, services, and providers (Schmitt, 2015c, 2015i).

On the other hand, considerable attention has been devoted towards aligning the PKM design elements with renowned concepts, methodologies, and heuristics in order to promote transparency and suitability, for example:

- Adopting Maslow's Extended Hierarchy of Needs, a PKM for Development (PKM4D) framework devised, differentiates the impact of the PKM concept according to twelve socially relevant criteria. While each of them positively impact on the individual (exciters \& delighters), their absence and the lack of other potentially appropriate tools will have detrimental effects (inhibitors \& demotivators). At an aggregated societal level, these criteria closely link to the various opportunity divides currently discussed (Schmitt, 2014k, 2015a).

- Positioned in the historic context of emerging knowledge types and human civilization, the PKM concept has been portrayed as a novel technology able to promote individualization as well as collaboration providing the basis for the 'Next KM Generation' as well as for a General-Purpose Technology (Schmitt, 2014b, 2015f, 2015h) or Disruptive Innovation (Schmitt, 2016g).

- Focusing on the educational synergies with the PKM concept (Schmitt and Butchart, 2014; Schmitt, 2014m, 2015k, 2016b, 2016f), dedicated presentations documented the methods adopted/adapted either in form of papers with extensive visualizations (Schmitt, 2013c, 2013e, 2013g, 2014a, 2016c), posters (Schmitt, 2013b, 2013d, 2014n) or demonstrations (Schmitt, 2014i).

- Utilizing the systems thinking techniques of the transdiscipline of Informing Science (IS), the PKMS design has been validated against Cohen's IS-Framework, Leavitt's Diamond Model, the IS-Meta Approach, and Gill's and Murphy's Three Dimensions of Design Task Complexity (Schmitt, 2015d). 


\section{PKM as a Means to deal with Growing Complexities}

The latter IS-framework validation exercise also followed up on three mission-critical questions:

- How would a system based on the personal knowledge management concept be able to better serve the growing creative class of knowledge workers and the innovation agenda of knowledge economies compared to current solutions?

- How can personal devices help in mastering the ever-increasing information abundance, the changing spheres of work, the widening digital and innovation divides, and the needs for self-development and e-collaboration?

- Given a widely quoted early KM definition as the process of capturing, distributing, and effectively using knowledge (Davenport 1994), how can such basic activities be redesigned to make a difference?

The answer aligned Gill's and Murphy's (2011) three dimensions of Design Task Complexity

- Objective Complexity referring to the number and dynamics of elements and their interrelationships, measured by Ruggedness,

- Unfamiliarity referring to the lack of structure, guidance, and/or task-specific knowledge as well as to inadequate tools, measured by Perceived Difficulty,

- Problem Space Complexity referring to the constraints, uncertainty, and irreversibility associated with the information processing and their solutions, measured by Path Entropy,

to the needs addressed by the PKMS features offered. Instead of increasing all three complexities without intervention, employing PKMS devices is able "to scale down each one of the complexities discussed in order to subsequently create 'productive' spaces for efficient storage, improved learning, assisted authorship, and innovative knowledge utilization which are able to better absorb and share prospective knowledge advances". Some of the complexity-reducing features have also been exemplified and visualized in a PKMS Design Task Complexity Cube (Schmitt, 2015d).

A subsequent article (Schmitt, 2015h) takes these findings further and assesses the prospect of whether the PKMS concept and prototype system has got what it takes to grow into a transformative General-Purpose-Technology. Based on criteria like, for example, a wide scope for improvement and elaboration (in people's private, professional and societal life), applicability across a broad range of uses in a wide variety of products and processes (in multi-disciplinary educational and work contexts), and strong complementarities with existing or potential new technologies (like organizational KM Systems and a proposed World Heritage of Memes Repository), the considerations also introduce a fourth complexity dimension with a focus on unsustainable developments ${ }^{1}$ and opportunity divides. Clustered into ten categories (advancement, systemics, transparency, productivity, performance, universality, shared aims, traceability, dominance, and spawning), the summarized conclusions extend over all four complexities and their intersections and a have been visualized in a chart of four overlapping circles (figure 1).

With this article's retrospective focus on the design thinking approach taken, the four complexity dimensions play again a pivotal role and are further examined in the next section in light of Popper's Three Worlds $(1972,1979)$. The article then introduces the notion of Theory Effectiveness and the significance of Design Science Research frameworks and guidelines for the discipline of Information Systems. The design thinking process leading to the PKMS concept and system is subsequently portrayed by fitting it to these guidelines and the 'three world' perspective.

\footnotetext{
${ }^{1}$ The notion of sustainable impact attracts increasing attention in Design Science Research (DSR). Gill and Hevner (2013), for example, propose complementing the research goal of usefulness with a fitness-utility model that "better captures the evolutionary nature of design improvements and the essential DSR nature of searching for a satisfactory design across a fitness landscape".
} 


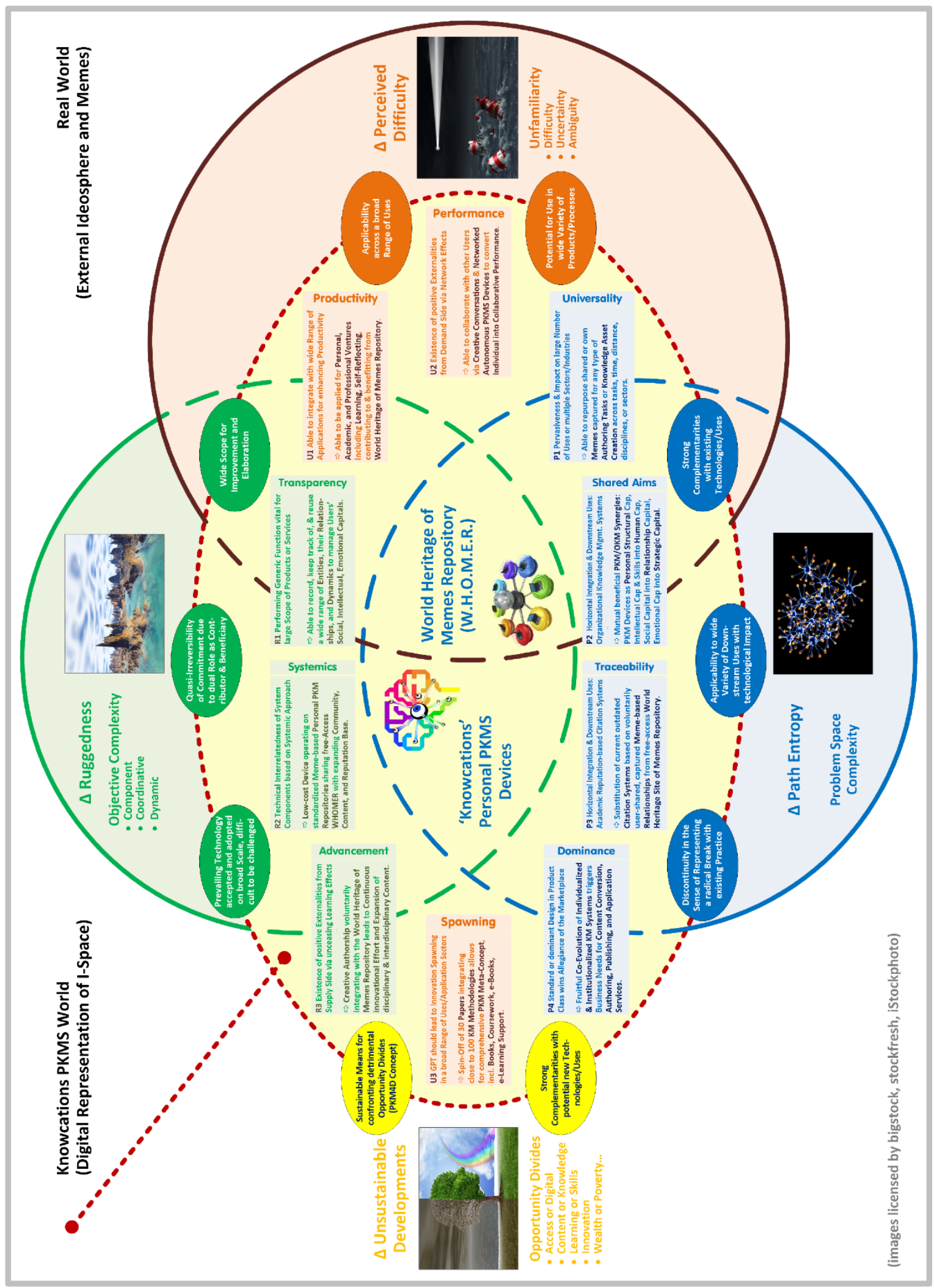

Figure 1: PKMS Design Task Complexities versus General-Purpose-Technology Attributes (Schmitt, 2015h). 


\section{Popper's Worlds as Three Distinct Spheres of Reality}

Popper's Three Worlds $(1972,1979)$ differentiate reality into three distinct spheres (figure 2). World: 1 comprises the concrete objects and their relationships and effects in the real physical world. World: 2 refers to the results of the mental human thought processes in the form of subjective personal knowledge objects. World:3 represents the thought content made explicit in the form of abstract objective knowledge objects which express the products of world: 2 mental processes. The arguments for PKM Solutions made previously in the context of technological progress (Schmitt, 2014b) are closely related to Popper's world view.

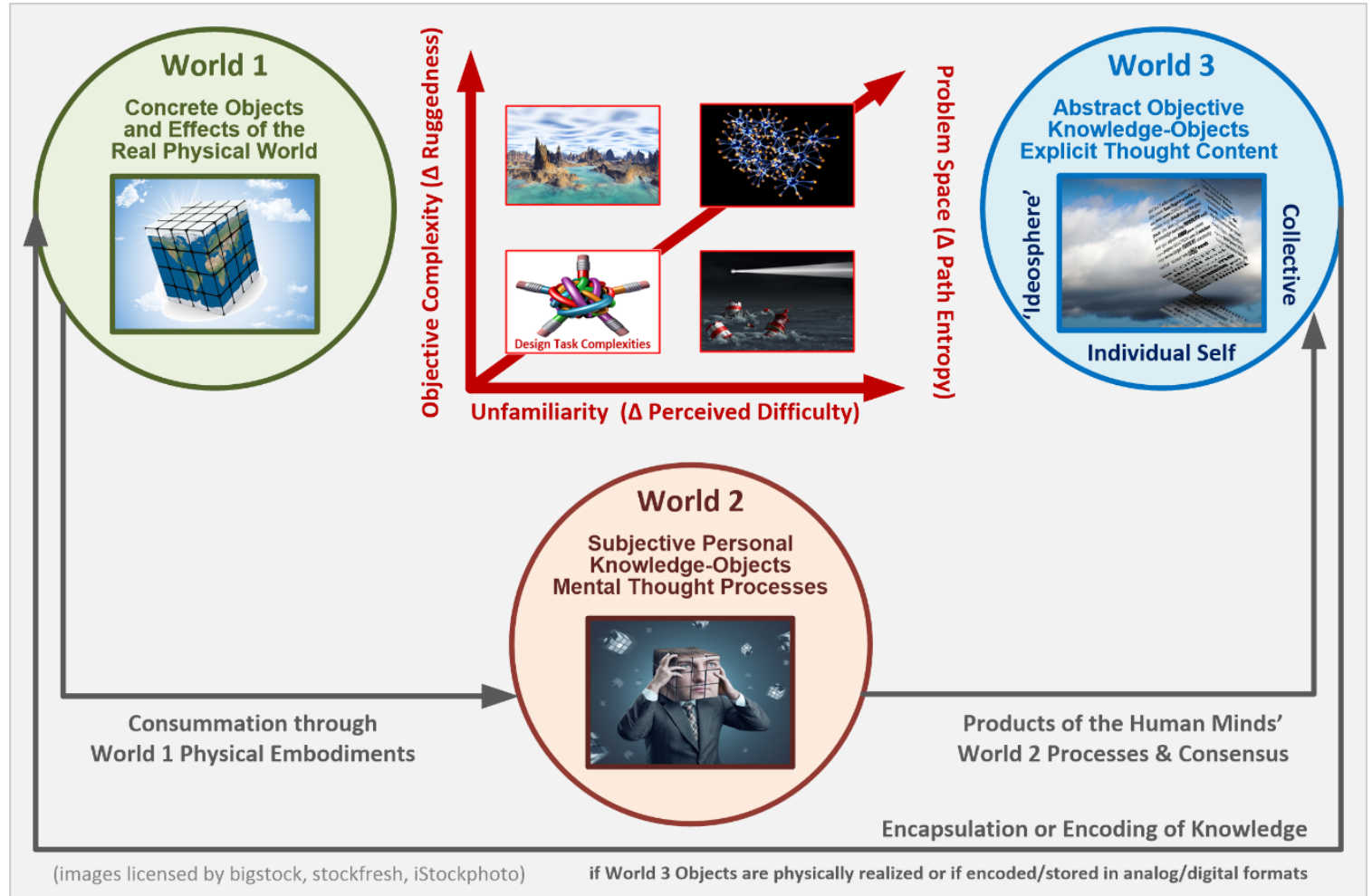

Figure 2: Popper's Three Worlds and Design Task Complexities encountered

- World:1's rising populations and higher innovation rates mean that not only the number of entities to deal with is growing, but that their potential relationships and effects are subjected to a combinatorial explosion and a mounting objective complexity. The accelerating change also renders physical and social technologies and their documented representations more rapidly obsolete than ever before. Accordingly, a PKMS's knowledge base structure has to be able to accommodate all entities and relationships deemed relevant and to keep track of any dynamic changes. The main emphasis is on Objective Complexity.

- Reflecting on which of one's acquired know-who/how/why/where/when/with/abouts might become outdated and directing one's attention to the relevant organizational, commercial, social and legal innovations, thus, becomes a pre-condition for keeping one's personal world: 2 knowledge capitals a-jour, for familiarizing oneself with the potential game changers, and/or for adding one's conclusions and ideas to the world: 3 extelligence ${ }^{2}$.

\footnotetext{
2 Stewart and Cohen (1999) introduced the term 'Extelligence' for externally stored information; it forms the external counterpart to the intelligence of the human brain/mind and deals in information whereas intelligence deals in understanding; together they are driving each other in a complicit process of accelerating interactive co-evolution.
} 
To support the underlying thought processes, a PKMS needs to conserve and monitor one's knowns and unknowns (Extended Ignorance Matrix (Schmitt, 2013e, 2015d)) and guide the knowledge acquisition, creation, and exploitation activities (PKM Value Chain (Schmitt, 2013c, 2015d)). The main concern is the Complexity related to Unfamiliarity. World:2 represents the mind of the knowledge worker following Gurteen's (2006) wider definition ${ }^{3}$.

- World:3 resembles a representation of the entire accumulated explicit human know-how and experience. For Popper (1972), only formulated thoughts can be shared and criticized. As abstract objective world:3 objects, these thoughts stand on their own, are independent of their creators, and should be judged on their own merit.

However, to elicit impact on world: 1 physical objects and/or other world: 2 minds, the abstract world:3 objects have to be resourcefully combined (path entropy) and physically embodied or realized in concrete world: 1 objects. They need to be incorporated into either inanimate vectors (such as buildings, machines, factories, products, software, storage devices, books, great art, or major myths) or living hosts (such as people, teams, corporations, or economies). PKMS functionalities, hence, have to support the underlying knowledge tracing, configuration, and creative authorship activities. The main focus shifts to deal with Problem Space Complexity. World: 3 represents - what has been termed in prior publications - the 'Ideosphere,

All three worlds are highly interactive: "World:2 acts as an intermediary between World:3 and World:1. But it is the grasp of the World:3 object which gives World: 2 the power to change World: 1" (Popper, 1979). The agents interacting between the worlds, as adopted and adapted by the PKMS concept, are memes, originally described as units of cultural transmission or imitation (Dawkins, 1976) that evolve over time through a Darwinian process of variation, selection and transmission. As explicit representations, memes add to the world:3 memory of human thinking.

But, in order to survive, memes have to be able to endure in a medium they occupy and the medium itself has to persevere. They can either be encoded in durable world:1 vectors spreading almost unchanged for millennia, or they succeed in competing for a host's world:2 limited attention span to be memorized (internalization*) until they are forgotten, codified (externalization*) in further world: 1 objects or spread by the spoken word to other hosts' world:2 brains (socialization*) with the potential to mutate into new variants or form symbiotic relationships (combination*) with other memes (memeplexes) to mutually support each other's fitness and to replicate together (*-markings refer to comparable SECI Model stages (Nonaka \& Takeuchi, 1995; Schmitt, 2014m, 2016b)).

${ }^{3}$ Gurteen (2006) places - rather than the socio-economic criteria of an individual's type of work as in Florida's (2012) Creative Class - the virtue of responsibility at the center of his reflections: "Knowledge workers are those people who have taken responsibility for their work lives. They continually strive to understand the world about them and modify their work practices and behaviors to better meet their personal and organizational objectives. No one tells them what to do. They do not take 'no' for an answer. They are self-motivated". To Gurteen's mind, they "cannot be coerced, bribed, manipulated or rewarded and no amount of money or fancy technology will 'incentivize' them to do a better job. Knowledge workers see the benefits of working differently for themselves. They are not 'wage slaves' - they take responsibility for their work and drive improvement".

${ }^{4}$ Memetics studies ideas and concepts viewed as 'living' organisms, capable of reproduction and evolution in an 'Ideosphere' (Sandberg, 2000), an "invisible but intelligible, metaphysical sphere of ideas and ideation" where we engage in the creation of our world. "This means that the substance of the world is idea, which forms, reforms, and transforms itself via the conversations of humankind, synergetically organizing itself as an evolutionary, multidimensional network [with technology just an artefact of idea]. The problem, as Kimura (2005) notes, is that the majority of 'humanity remains the consumer of ideas without being the producer". Hence, what is called for is an ideospheric transformation set off by a synergetic phenomenon that emerges "when individuals in sufficient numbers become authentic, independent thinkers, that is, originators of ideas, producers of dialogues, and contributors to the network of conversations that comprises the world". 


\section{PKM - From Conceptual Model to Prototype System}

In "Towards an Ontology of Innovation Models", O'Raghallaigh, Sammon, and Murphy (2011b) bemoan that most - including even the latest - management concepts and models "emanating from the academic discourse fall well short of organizational reality" and that only few "are ever translated into software-based tools." In a prior paper (2011a), the same authors therefore plead for designing a concept of Theory Effectiveness which characterizes a theory "that is incrementally and iteratively designed in order to be purposeful - both in terms of its utility (which is largely a matter of content) but also in its communication (which is largely a question of presentation) to an audience."

Thus, in addressing the problems of logic and objectivity in science, O'Raghallaigh et al. (2011a) introduce the 'big-T theory' labeling a world: 3 semi-linear abstract object derived from a scholar's nonlinear world: 2 vision. Various elements of this 'big-T theory' might then need to be embodied into subsets as 'small-T theories', the label assigned to world: 1 concrete objects such as research papers, conference presentations, or prototypes. While the 'big-T theory' is critical to representing aspects of a reality, the 'small-T theories' are critical to disseminating to an audience an understanding of that reality. The ensuing criticism of the social interactions may result in the 'big-T theory' being discarded, being re-conceptualized, or seeking further justification.

In following the modus of 'theory falsification' (Popper, 1959), the quality of the 'big-T theory' can only be determined indirectly via its 'small-T theories' embodiments, either from the reaction by peer reviewers or an audience or from their impact on world: 1 objects. Notwithstanding the struggles of closely aligning the vision with its 'big- $T$ ' and 'small-T' counterparts and of promoting theory generalization or contextualization, O'Raghallaigh et al. (2011a) point to the endemic failures of engaging in research relevant to the needs of stakeholders and to the endemic failures of adequately translating knowledge for the relevant audiences' fruitful consumption. Achieving theory effectiveness, thus, requires placing utility and communication at the core of all theory.

Peffers, Tuunanen, Rothenberger, and Chatterjee (2007) attribute these shortcomings to the still dominant traditional descriptive research paradigm of the social and natural sciences: "While design, the act of creating an explicitly applicable solution to a problem, is an accepted research paradigm in other disciplines, such as engineering, it has been employed in just a small minority of research papers published in our own best [information systems research] journals to produce artefacts that are applicable to research or practice." To solve this dilemma, Peffers et al. propose a design science research methodology (DSRM). Its aim is to establish a commonly understood framework, so that design science research in Information Systems is more easily "accepted as valuable, rigorous, and publishable in Information Systems research outlets" instead of needing to justify "the research paradigm on an ad hoc basis with each new paper".

The DSRM framework follows the six guidelines for conducting well carried out Design Science (DS) research provided by Hevner, March, Park, and Ram (2004). These guidelines form the basis for further structuring the retrospective perspective and considerations of this article. 


\section{PKM versus Design Science Research Guidelines}

Hevner et al. (2004) motivate their DS research guidelines (table 1) also as a reaction to the lacking impact of information systems research on business practices or organizational capabilities and to the unsuitable presentations already alluded to. Their aim is to supplement the reactive behavioral (natural) science paradigm with the proactive design science paradigm in order to support information technology (IT) researchers in creating innovative IT artefacts that extend human and social capabilities and meet desired outcomes. However, since "simply creating a new IT artefact for extant organizational problems does not necessarily constitute good research", the guidelines are meant to provide a roadmap for conducting and criteria for evaluating DS research in IT. In the context of this article, their intended purpose is applied to the PKM project.

\begin{tabular}{|c|c|c|}
\hline \# & Guideline & Focus Area \\
\hline G1 & $\begin{array}{l}\text { Design as } \\
\text { an Arte- } \\
\text { fact }\end{array}$ & $\begin{array}{l}\text { The designed artefact (e.g. construct, model, method, or instantiation) must be } \\
\text { effectively represented, enabling evaluation and comparison with existing arte- } \\
\text { facts created for the same purpose as well as enabling implementation and ap- } \\
\text { plication in an appropriate environment to demonstrate feasibility. The critical } \\
\text { nature of DS research in IS lies in the identification of new IT capabilities, } \\
\text { resulting in the expansion into new realms with significant impact. }\end{array}$ \\
\hline $\mathrm{G} 2$ & $\begin{array}{l}\text { Design as } \\
\text { a Search } \\
\text { Process }\end{array}$ & $\begin{array}{l}\text { Effective design requires knowledge of both the application domain (e.g. re- } \\
\text { quirements and constraints) and the solution domain (e.g. technical and organ- } \\
\text { izational). Due to the complexities involved, effective problem solutions bene- } \\
\text { fit from systematically utilizing heuristic search strategies, including decom- } \\
\text { position, abstraction, analogies, and iterative and incremental approaches with } \\
\text { no well-defined stopping rules. }\end{array}$ \\
\hline G3 & $\begin{array}{l}\text { Problem } \\
\text { Relevance }\end{array}$ & $\begin{array}{l}\text { Purposeful IT artefacts are created, applied, assessed, and improved to address } \\
\text { important and relevant heretofore unsolved problems by supporting the practi- } \\
\text { tioners who plan, manage, design, implement operate, and evaluate the result- } \\
\text { ing information systems and/or their outputs. Criteria for assessing relevance } \\
\text { focus on representational fidelity and implementability. }\end{array}$ \\
\hline G4 & $\begin{array}{l}\text { Research } \\
\text { Rigor }\end{array}$ & $\begin{array}{l}\text { DS is a creative and often iterative problem-solving process which has to make } \\
\text { effective use of the DS theoretical foundations and methodologies. A construc- } \\
\text { tion and evaluation of a design artefact need to be based on rigorous methods } \\
\text { (e.g. empirical methods, mathematical formalism, or deductive logic). Rigor } \\
\text { must be assessed with respect to the applicability and generalizability of the } \\
\text { artefact and its performance metrics within the overall human-machine prob- } \\
\text { lem-solving system. }\end{array}$ \\
\hline G5 & $\begin{array}{l}\text { Research } \\
\text { Contribu- } \\
\text { tions }\end{array}$ & $\begin{array}{l}\text { Effective design science research must provide clear contributions in the areas } \\
\text { of the design artefact, design construction knowledge (theoretical foundation), } \\
\text { and/or design evaluation knowledge (evaluation methodologies). }\end{array}$ \\
\hline G6 & $\begin{array}{l}\text { Design } \\
\text { Evalua- } \\
\text { tion }\end{array}$ & $\begin{array}{l}\text { A design artefact is complete and effective (utility) when it satisfies the re- } \\
\text { quirements and constraints (functionality) of the problem it was meant to solve } \\
\text { (performance). Its quality and efficacy must be rigorously demonstrated via } \\
\text { well-executed evaluation methods. Good designs embody a style that is aes- } \\
\text { thetically pleasing (elegance) to both the designer and the user (usability) and } \\
\text { that fits with the technical infrastructure of its environment (consistency, accu- } \\
\text { racy, reliability). Design evaluation includes observational, analytical, experi- } \\
\text { mental, and testing methods. }\end{array}$ \\
\hline
\end{tabular}




\section{PKMS Design as a Set of Novel Artefacts (G1)}

March and Smith (1995) differentiate research outputs according to instantiations, models, methods, and constructs. The prototype system-in-progress represents the major instantiation of the PKM concept as the realization of a novel working world: 1 IT artefact rooted in the personal, educational, and professional environment of knowledge societies. Its aim is to demonstrate the feasibility and effectiveness of the underlying models, methods, and constructs which operationalize the world:3 'big-T theory'. Supporting further instantiations include world: 1 'small-T theories' in form of the publications and presentations alluded to.

Models are representations of how things are or how they ought to be, while Methods are sets of steps (guidelines or algorithms) to be taken to perform a task. Over a hundred renowned models and methods have been incorporated in the PKMS design including their adjusting, extending, repurposing, or merging. In the process, a set of enriched or novel models have been coined and visualized, including a comprehensive three-dimensional Information Space depicting the internal and external PKM environment, an Extended Ignorance Matrix, a PKM Value Chain, a PKM for Development Framework, and a Dynamic Meme Reuse and Modification Model. Most of these models are represented as transparent maps able to integrate and depict methodological sequences of processes and events, including cycles of learning and waste, foraging and sensemaking loops.

Constructs or Concepts form the specialized language and shared knowledge of a particular domain or problem environment. However, as a support tool for life-long learning (Schmitt \& Butchart, 2014) and as an "Artefact and Expediter of Interdisciplinary Discourses" (Schmitt, 2015g), the PKM concept and system strive towards multi- and transdisciplinary applicability. To promote this aspiration, the publications (Schmitt, 2012-2015k) have been disseminated to and received feedback from a wide range of disciplines via journal and conference submissions covering Knowledge Management and Information Science, Technologies and Innovation, Social Sciences and Management, Human Resource Development and Organizational Change, Higher Education, Sustainable Development, Creativity, Cybernetics, Systems Thinking, and Future Foresight. The scope of language and knowledge is further broadened by integrating concepts of evolution and memetics as well as by engaging in KM's extensive use of analogies and metaphors.

Stringently defined - in contrast - are the types of entities and dynamic relationships which govern the structure and operations of the PKMS knowledge base. Able to represent world:2 ideas and world: 1 objects and classifications as well as their higher-order combinations (e.g. documents, authorship, ownership, organizational structures), the novel PKMS devices facilitate the features of Bush's 'Memex' envisioned seven decades ago. They act as enlarged intimate supplements to our memory and enable us to store, recall, study, and share the "inherited knowledge of the ages" relevant to us. They facilitate the addition of personal records, communications, annotations, contributions as well as non-fading trails of our individual interest through the maze of materials and memes available; all to be easily accessible and shareable with the PKMSs of acquaintances. As a consequence, the traceability of knowledge significantly improves, since "the inheritance from the master becomes, not only his additions to the world's record, but for his disciples the entire scaffolding by which they were erected" (Bush, 1945).

\section{PKMS Design as an Iterative Heuristic Search Process (G2)}

World:3 'big-T theories' and their respective world:1 'small-T theories' must be closely fitted to an author's world: 2 vision and firmly rooted in observations and understandings of world: 1 . They also must be carefully and methodically crafted to meet utility and communication expectations. All design elements are closely interrelated and any change in one area inevitably elicits effects on all the others. The high level of complexity in the solution domain is further heightened by the diversity of scholarly work in KM's inter-disciplinary application domain. 
The design of a PKM system fits into the category of so-called "wicked" problems, defined by Rylander (2009) as open-ended in the sense "that they are ill defined and characterized by incomplete, contradictory, and changing requirements and complex interdependencies and that the information needed to understand the problem depends upon one's idea for solving it." To solve such a problem, Stanford's D-School (2015) suggests an iterative process approach of empathizing, defining, ideating, prototyping, and testing.

However, particular to this PKMS-related case and its design cycles has been that the client, user, analyst, designer, and developer roles all reside in the one person of the author. The steps taken as part of each of the iterative design cycles have been adapted accordingly and have resulted in the A-B-C-D-E-F Steps which define any of the individual cycles within an iterative PKMS Design Process (figure 3 ) to be introduced below.

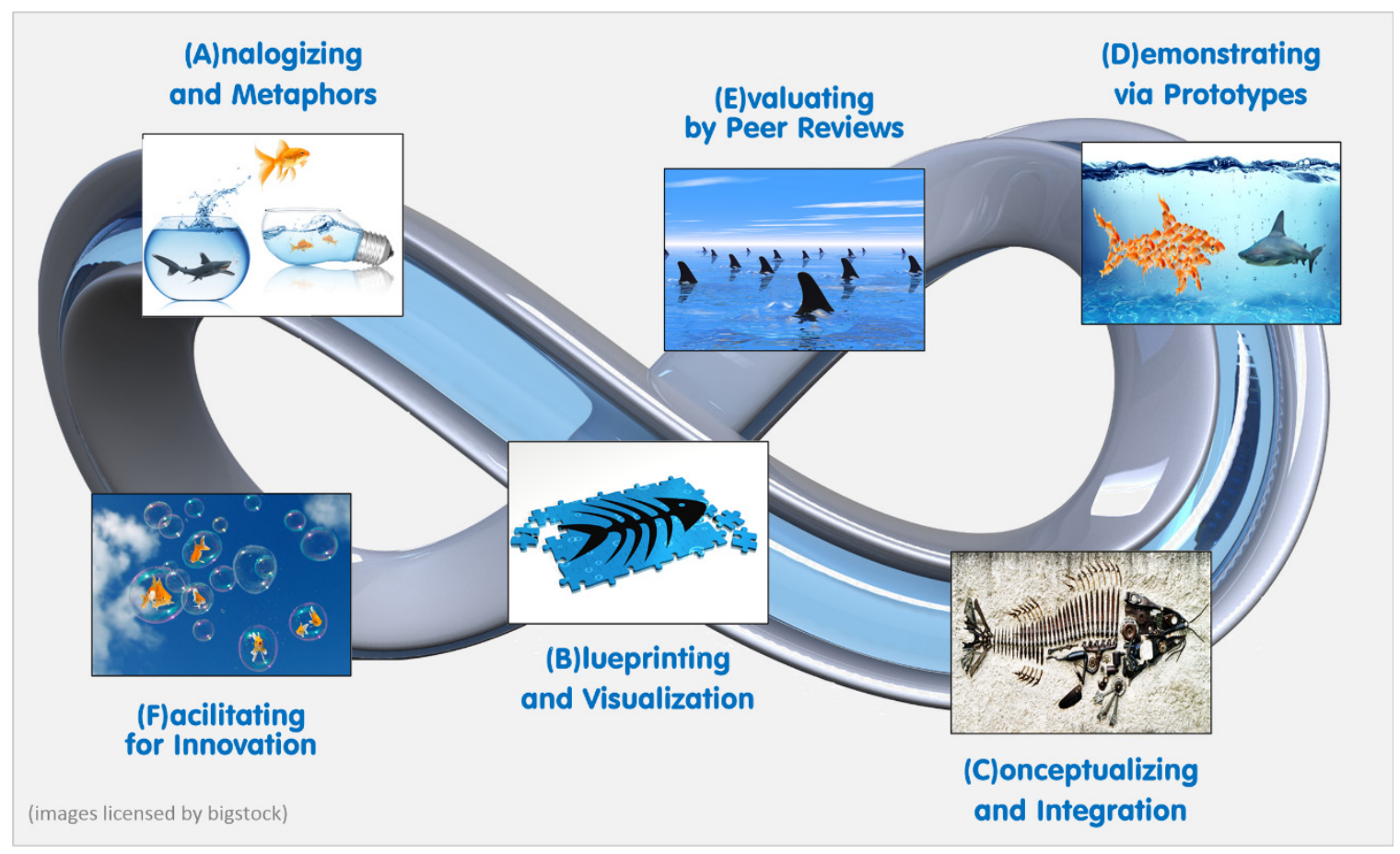

Figure 3: A-B-C-D-E-F Steps of any Single Cycle in the Iterative PKMS Design Process

\section{Step A: Analogizing and Metaphors}

Knowledge and its management are abstract concepts with no clearly delineated structure and no 'real world' referent. To apply structure and make them comprehensible requires the mapping of familiar notions of other disciplines to the one to be illuminated by means of analogical thinking and graspable metaphors. By, for example, analyzing two classic chapters in the KM literature, Andriessen (2006) detects twenty-two metaphors able to populate alternative continuums from physical to abstract, from tangible to intangible, and from static to dynamic knowledge. Similarly, the first step of each phase determines the adequate metaphors on which subsequent considerations are based. 


\section{Step B: Blueprinting and Visualization}

The management of knowledge is governed by an ill-structured mishmash of complementing as well as conflicting interdisciplinary methodologies and based on physical and social technologies which too often struggle to achieve their stakeholders' objectives due to diverse scholarly contributions, repetitive polemic discourses, and misguided organizational system generations. To facilitate understanding, the portrayal of potential better solutions cannot be accommodated by onedimensional linear text alone but necessitates the utilization of visuals, charts, and blueprints for the concept as well as the use of colors, icons, and catchy acronyms to support the humancomputer-interaction of the final system.

\section{Step C: Conceptualizing and Integration}

The 'write-only-after-you-can-picture-it' advice also includes the successful navigation of the intrinsic complexities mentioned. The quest for an all-embracing high-level system concept and design has to unearth feasible solutions in regard to the many methodologies advocated by scholars and practitioners. Fortuitously, what might have appeared initially as difficult to reconcile or at odds (e.g. KM's objectives, philosophies, and methods) has been integrated into sub-systems serving an overarching system architecture, covering the over one hundred renowned KM models and methods mentioned earlier.

\section{Step D: Demonstrating via Prototypes}

The conceptualization of the sub-systems and their interfaces have to be validated by the programming of adequate knowledge base structures, workflows, and user interfaces. Since one of the PKMS objectives is to support authorship, the own and cited ideas and memes constituting the PKM-related papers published also form the test data for the PKMS functionalities and repository. The familiarity with the content and how it is related eases evaluating the test results as well as any reconfiguration of knowledge base structures or workflows prompted by subsequent design decisions to adjust or add system functionalities.

\section{Step E: Evaluating by Peer Reviews}

With a prototype system in a continuous flux of development, the feedback from publications becomes a major determinant of quality assurance with the peer reviewers and audiences unconsciously taking up the role of an extended multi-disciplinary development team. In line with the interdisciplinary nature of the PKMS, the publications at the wide disciplinary range of conferences and journals assure a diversity of feedbacks. The approach also allows for further inspiration by attending other delegates talks and peer-to-peer discussions.

\section{Step F: Facilitating for Innovation}

Although this step predominantly features in the last phase prior to the marketing and distribution of the final product, many related activities can be addressed earlier. With the papers captured in the PKMS repository and the individual publications pitched at particular contexts of analogies, blueprints, and sub-concepts, any content can be easily repurposed for presentations as an individual book chapter and face-to-face or e-learning course unit. This captured knowledge also provides the means for the PKM system's help and tutorial functions as well as the initial stock of PKMS knowledge bases providing content to be potentially integrated into users' own publications. Terms, color schemes, icons, logos, slogans, and trademarks are also (pre-)determined in the earlier phases easing the subsequent tasks of creating business and communication plans, funding or cooperation proposals. 


\section{PKMS Relevance serving Communication and Utility (G3)}

While envisaging a potential KM revolution that gives more power and autonomy to individuals and self-organized groups, Levy (2011) suggests a personal discipline for collection, filtering and creative connection (among data, among people, and between people and data flows) and regards the sustainable growth of autonomous capacities in Personal KM as the most important function of future education. Wiig (2011), as pointed out earlier, recognizes the PKM root objective as the desire to make citizens highly knowledgeable. The quality and extent of individuals' competences and the structural Intellectual Capital (IC) assets available to them determine the realized performance of enterprises and societies. By the same token, Bedford (2012) expects KM education to provide the key opportunities for growing a $21^{\text {st }}$ century knowledge society, just as business, engineering and science education still do for the industrial economy.

Already, the spheres of work and careers have changed dramatically (World Bank Institute, 2008; Gratton, 2011; Florida, 2012). In parallel, an uneven diffusion of digital technologies has caused detrimental opportunity divides across societies worldwide (Drori, 2010; Johri and Pal 2012; Giebel 2013). "It is [now] crucial that all countries, large and small, rich and poor, take advantage of science, technology and innovation as fundamental elements for their development strategies, poverty reduction and the construction of a Knowledge Society" (OAS, 2005). 'Future of Employment' studies (Frey \& Osborne, 2013; Bowles, 2014) still estimate that half of today's employment (US and EU) is at risk due to the emerging 'Industrial Internet' (Evans \& Annunziata, 2012) and due to recent technological breakthroughs able to turn previously non-routine tasks into well-defined problems susceptible to computerization. An impact of this magnitude would necessitate a reallocation of workers towards tasks less susceptible with the likely prioritization of creative and social intelligence.

Individual, institutional, and societal pressures for greater flexibility and skill sets are clearly set to further grow. Extelligence, however, only generates competitive advantage if it is accessible and augmentable by individuals who know how (Stewart \& Cohen, 1999). Personal and organizational life would have been so much easier, if Bush's seven decades old vision of the 'Memex' had materialized already (Bush, 1945; Kahle, 2009; Davies, 2011; Osis \& Gaindspenkis, 2011).

But, so far, KM initiatives been pre-dominantly enterprise-based. They view knowledge as a foremost strategic asset to be measured, captured, stored, and protected. Complementing this technology-dominated first generation, a more practice-based and community-centered approach has emerged as a second phase in the last decade characterized by social media and the cloud (Schmitt 2015f). On the one hand, this adjustment is owed to the ICT-related organizational, commercial, social, and legal innovations alluded to. On the other hand, it is due to too many KM initiatives not delivering on their promises (Wilson 2002; Schuett 2003; Malhotra 2004; Pollard 2008; Frost 2013). Due to the deficiencies experienced, an experts' consensus about focal points for the 'Next KM' generation seems to be emerging: the "Use of Existing and Creation of New Knowledge" and the "Personal and Social Nature of Knowledge" (Grant and Grant 2008). A recent study among $222 \mathrm{KM}$ experts worldwide confirms these trends (Heisig 2014) and its ITrelated findings stress the growing importance of enabling interactive KM technologies and research priorities of combining human and technological factors, of effectively using appropriate tools and systems, of focusing on practical relevance, and of being able to predict the benefits and risks of 'the next big thing' rather than merely presenting retrospective deliberations (Sarka, Caldwell, Ipsen, Maier, and Heisig 2014).

The PKM concept proposed, the prototype-system-in-progress, the currently around thirty publications together with their envisioned book, tutorial, and coursework 'spin-offs' address all these pertinent problems by addressing educational and professional needs and by tackling opportunity divides independent of space (e.g. development countries) or time (e.g. life or career phase). 


\section{PKMS as Rigorously Systemic/Systematic Design Process (G4)}

The references to the prior work of other authors above represent just a subset of the combined publications' bibliography; they exemplify the inter-disciplinary relevance and coverage as well as the rigor with which prior relevant scholarly contributions and current empirical findings have informed and shaped the PKM-related research and design processes. After several iterative cycles of the A-B-C-D-E-F steps portrayed (figure 3), the multi-disciplinary substantial feedback from audiences and peer reviewers has helped consolidating the work presented to aid a systemic PKMS approach across disciplinary boundaries. The steps and cycles also allowed for the incremental adjustments of the overall 'big-T theory' in a systematic and coherent manner and for adapting and fine-tuning the plans for the roads ahead.

"Scholarship is an inherently social activity, involving a wide range of public and private interactions within a research community. Publication, as the public report of research, is part of a continuous cycle of reading, writing, discussing, searching, investigating, presenting, submitting, and reviewing. No scholarly publication stands alone" (Borgman, 2007). In the PKMS context, the notion of 'Standing on the Shoulders of Giants' is following four major motivations:

Firstly, "although the novel PKMS concept aims at departing from the centralized institutional developments and at strengthening individual sovereignty and personal applications, it is not meant to be at the expense of Organizational KM Systems, but rather as the means to foster a fruitful co-evolution" (Schmitt, 2014k). This aim is based on mutually beneficial interests of $\mathrm{PKM}-\mathrm{OKM}$-users in collectively harvesting prior accumulated knowledge subsets and in converting individual into organizational performances. This endeavor requires a solid common ground of renowned and accepted KM methodologies and practices (Schmitt, 2015f, 2015b, 2016d).

Secondly, the KM-relevant record available (as further portrayed under Step B) is governed by an ill-structured mishmash of complementing as well as conflicting interdisciplinary methodologies. Establishing a common ground, necessitates not only a stringent evaluation and selection of the many solutions advocated by scholars and practitioners, but frequently requires their adjustment, extension, re-purposing, or merging in order to proceed towards an integrated PKM system architecture. For example, the Personal Knowledge Management for Development (PKM4D) framework, briefly mentioned in the introduction, has been one of the outcomes in this endeavor. It breaks down the features of the PKM approach into twelve distinct benefits for individuals, but also points out the negative effects if support for any of the sub-features is not available (Schmitt, 2014k, 2015a). As a tool closely interrelated with Maslow's Extended Hierarchy of Needs, the PKM4D framework also provides the basis for cross-referencing the personal sphere of the individual with the educational, professional, organizational, and developmental spheres at an institutional level. Not only can the applicability and generalizability of the PKM System in the relation to individual Knowledge Workers be differentiated and demonstrated, they also can be assessed, aggregated, and compared with other support scenarios to assist in the developmental context of businesses and agencies.

Thirdly, to quality assess and assure the PKMS design, its processes have been validated against established concepts and methodologies (Schmitt, 2013c, 2013g, 2014a, 2014e, 2015a, 2016c) including 'Mapping of the Agent and the World' (Boisot, 2004), 'Intelligence versus Extelligence Concept' (Stewart \& Cohen, 1999), 'Notional Model of the Sensemaking Loop for Intelligence Analysis' (Pirolli \& Card, 2005), 'SECI-Spiral' (Nonaka \& Takeuchi, 1995), 'Eight Building Blocks of KM' (Probst, 1998), 'Creative Space' and 'Seven Waterfall Model' (Wierzbicki \& Nakamori, 2006, 2007). A recent article (Schmitt, 2015d) employed the systems thinking techniques of the transdiscipline of Informing Science (IS). By applying the IS-Framework and the IS-Meta Approach (Cohen, 1999, 2009), the Change (Diamond) Model (Leavitt, 1965), and the 
Design Task Complexity Model (Gill \& Murphy, 2011), the more specific KM models and methodologies central to the PKM system concept were aligned, introduced, and visualized.

Fourthly, a PKMS merges distinctive knowledge objects/assets of diverse disciplines into a single unified knowledge repository. In following the PKMS concept's aim to contribute to educational development, all PKMS publications and their references already form part of the prototype's knowledge repository. Their meme-based representations are based on - as Bush (1945) put it "an extensive mesh of associative multidisciplinary trails already built-in of alternative pathways" which can be handily tracked and further explored by a PKMS user community to become subsequently part of their own contributions to PKMS repositories. This mesh will also conveniently accommodate the establishment and navigation of PKMS e-learning modules planned following the face-to-face course design. Moreover, the integration of the over one hundred KM tools and ideas into the PKMS concept allows for KM education in a transparent and coherent manner, including the rationale how and why some of the original methods had to be adjusted, extended, re-purposed, or merged.

\section{PKMS as Research Dis-contributing to Unsustainability (G5)}

Many of the envisaged benefits of the PKMS concept and implementation have been explicitly and implicitly referred to in the previous sections. Following a personal (rather than organizational), bottom-up (instead of top-down), meme-based (complementing document-centric), and creative-conversation-focused (versus fragmented and silo-prone fixated) approach introduces an innovative constellation to the KM domain and technologies. Its novel methodologies and features have been detailed in respect to overcoming current constraints and barriers (Schmitt, $2014 \mathrm{~b}, 2014 \mathrm{f}$ ) and to their potential to change personal (Schmitt, 2015d), organizational (Schmitt, 2015f, 2015c, 2015i), and societal (Schmitt, 2015a) KM perspectives and practices. Due to this change potential, it also has been looked at from the perspective of Kuhn's ideas (1970) related to paradigms and scientific revolutions (Schmitt, 2015d), from the point of view of general-purposetechnologies (Schmitt, 2015h), and disruptive innovations (Schmitt, 2016g). With references to the theoretical foundation also made and with the evaluation methodologies to follow, this subsection attempts to provide a bird's eye three world view to add a high-level strategic perspective to these considerations. It is informed by the fourth complexity dimension introduced earlier (figure 1) in order to focus on unsustainable developments and opportunity divides.

A prior paper (Schmitt, 2014b) argued that human progress can be attributed to five co-evolutions which effectively dealt with successive emerging constraints at their respective stages (figure 4):

- Embodied and embrained knowledge were the results of a gene-brain-co-evolution propelled by ever more creative memes (Dawkins, 1976; Distin, 2005); Koch, 2001).

- Encapsulated and encultured knowledge stem from the notion of physical and social technologies supported by ever more complex plans (Beinhocker, 2006).

- Encoded and organizational knowledge required external storage devices (analog) and collective intelligence backed by accumulating extelligence (Stewart \& Cohen, 1999).

- Digitized and networked knowledge needed digital external storage devices and information connectivity built up by mounting digital extelligence.

- Enclouded and value-chained knowledge is about to take the center stage based on cloudbased memory and applications linked to cyber-physical systems and self-organizing value chains driven by the growing generation and impact of big data.

Putting it in Popper's terms: A recurrent pattern of emerging limitations (World:1 physical artefacts and storage devices) imposed constraints on human intermediaries (World:2 processing and understanding) to further advance the world's accumulated record (World:3 knowledge object drivers) for feeding wide-scale technological progress (World:1 physical object innovations). 


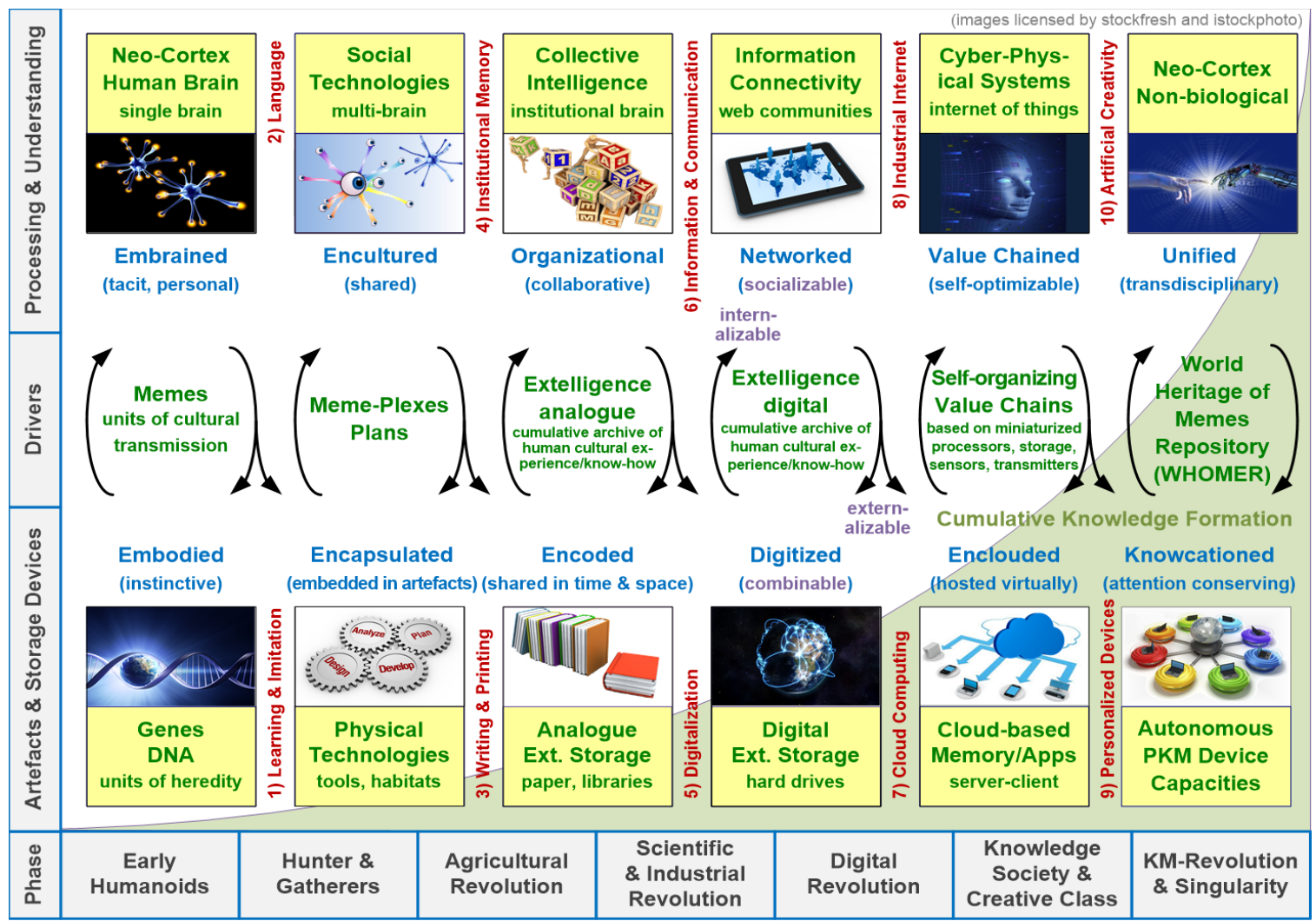

Figure 4: Five Co-evolutions shaping Human Progress and a possible Scenario (Schmitt 2014b)

Only particular general-purpose technologies (language, writing, printing, institutional record keeping, digitization, ICT, cloud computing, and the industrial internet) were and are able to overcome these constraints often only after profound periods of stagnation and disorientation exaggerated by ignored needs to abandon lock-ins, shift paradigms, change habits, and innovate.

Focusing on the current constraint, the pattern has changed. In terms of World:1, the dominant cause of problems rests no longer in the limitations of its objects but in the ever-increasing abundance of a particular type of objects, like books, web content, digital records, or documents (to which this article contributes). It means that World: 2 processing and understanding is not any more hampered by the scarcity of sources and content available but by their sheer ever-increasing numbers and volume (Short, Bohn, \& Baru, 2011; Hilbert, 2011, 2014) which overload the world: 2 finite scarce human attention capacity available 5 . This currently unsolved and unsustainable situation can be summarized by paraphrasing Popper (1979): With the world:2 mind shortchanged of a thorough grasp of the World:3 object due to overwhelming world: 1 object redundancy, fragmentation, inconsistency, untraceability, corruption, and decay, the World:2 power for world: 3 innovations and World: 1 change is diminishing at a disturbing rate (figure 5).

\footnotetext{
5 In 'Designing Organizations in an Information-rich World', Simon (1971) pointed out that the "wealth of information creates a poverty of attention and [with it] a need to allocate that attention efficiently among the overabundance of information sources that might consume it". Thus, "it is not enough to know how much it costs to produce and transmit information; we must also know how much it costs, in terms of scarce attention, to receive it. [...] In a knowledgerich world, progress does not lie in the direction of reading information faster, writing it faster, and storing more of it. Progress lies in the direction of extracting and exploiting the patterns of the world - its redundancy - so that far less information needs to be read, written, or stored".
} 


\begin{tabular}{|c|c|}
\hline \multicolumn{2}{|r|}{ Table 2: Overview of the Iterative PKMS Design Process Cycles } \\
\hline 1 & $\begin{array}{l}\text { One's Personal Motivations, Burdens, and Obstacles: Having explored the challenges and } \\
\text { motivations as described in the PKM4D framework, the broader aims of the PKMS were } \\
\text { defined. The farming metaphor describes a PKMS space, where prior knowledge will pro- } \\
\text { vide the potentially limitless soil, learning and research the life-spending water, own new } \\
\text { memes and ideas the fertilizer, re-combinations and mutations the farm work, collabora- } \\
\text { tors' and supervisors' memes the helping hands, publications and presentations the crop, } \\
\text { and the shared harvest is represented by knowledge dissemination leading to adaptations, } \\
\text { co-operations, and innovations. The digital PKM quartermaster will guard the fruits and } \\
\text { show the way for mastering the interdependent and iterative cycles. However, several barri- } \\
\text { ers were identified which explain the current absence of PKMS devices which led to speci- } \\
\text { fying six vital provisions or pleas for their establishment. }\end{array}$ \\
\hline 2 & $\begin{array}{l}\text { One's Knowledge-related Playing Field: As a basis for many of the subsequent blueprints, } \\
\text { Boisot's three-dimensional Information-Space Model has been adopted. Its role is to visual- } \\
\text { ize the integration of several KM methodologies as well as the workflows of the PKMS } \\
\text { system and to position relevant knowledge types and assets. As a result, a map of the 'Ide- } \\
\text { osphere' emerges which resembles 'ba', the 'spaces' where thoughts, theories, and ideas } \\
\text { evolve and are communicated or documented. }\end{array}$ \\
\hline 3 & $\begin{array}{l}\text { One's Knowledge-related Capitals to develop: Knowledge workers are advised to develop } \\
\text { their skills and competencies as well as their intellectual, social, and emotional capitals. } \\
\text { The related tasks, entities and learning cycles had to be clearly specified for integration into } \\
\text { the PKMS's 'Ideosphere' and 'Spaces' concept. But, knowledge is a perishable good } \\
\text { threatened by becoming forgotten or outdated. Accordingly, the extension of the ignorance } \\
\text { matrix attained central importance in blueprinting the value chain connecting PKMS users } \\
\text { with the 'Ideosphere'. The notion of memes acquired similar status: If memes and their in- } \\
\text { built ideas are able to flourish in a virtual 'Ideosphere' as their habitat of operation, PKM } \\
\text { Systems aiming at supporting individual capacity and repertoire for innovation, sharing and } \\
\text { collaboration are well advised to utilize the very same space and resources and to form a } \\
\text { digital counterpart of this 'Ideosphere'. }\end{array}$ \\
\hline 4 & $\begin{array}{l}\text { One's Contributions to the Progress of the World: Knowledge is socially constructed. On } \\
\text { the one hand, we are the beneficiaries of the performance of others, of organizations and } \\
\text { society; on the other hand, we are also meant to contribute. Accordingly, this phase exam- } \\
\text { ines the potentials of creative conversations between PKMSs and PKMS-OKMS collabora- } \\
\text { tion. It assesses the possible impact supported by a proposed central 'World Heritage of } \\
\text { Memes Repository (WHOMER)' on scholarship, interdisciplinary discourses, knowledge } \\
\text { traceability, and reputation-based citation systems. It further validates the PKMS concept } \\
\text { against the Information Science and Design Task Complexity Frameworks and evaluates it } \\
\text { in the context of human civilization, general-purpose technologies, disruptive innovations, } \\
\text { and scientific revolutions. }\end{array}$ \\
\hline
\end{tabular}

The new bottleneck's inefficiencies and contributing barriers have been identified (Schmitt, 2014f) and the PKMS design thinking process circumnavigated four iterative A-B-C-D-E-F design cycles (table $2^{6}$ ) to propose a solution able to escape the current lock-in situation.

\footnotetext{
${ }^{6}$ Attentive observers will notice that the chronology of publications does not strictly match the sequence of the iterative cycles presented. The justification for these a-synchronous timelines has been the author's ambition to give some earlier conceptual ideas the time to mature sufficiently, in regard to the compatibility to parallel conceptual developments as well as to the distinctive terms (in the overall PKM system context) to be applied for their dissemination. From today's point of view, this course of action has paid off since only a minor number of aspects reported in earlier papers had to be revised.
} 
The solution proposed by the PKMS concept follows three central leitmotifs:

- If memes and their inbuilt ideas are able to flourish in a virtual 'Ideosphere' as their habitat of operation, PKM Systems aiming at supporting individual capacity and repertoire for innovation, sharing and collaboration are well advised to utilize the very same space and resources and to form a digital counterpart of this 'Ideosphere' (Schmitt, 20141, 2016a).

- If the overall performance and viability of societies and enterprises result from innumerable small actions by individuals, from the quality and extent of their competences and the structural Intellectual Capital assets available to them, then - as a prerequisite - people must also be provided with the resources and opportunities to do their best (Wiig, 2011).

- If the future of work and knowledge societies is based on the notion that knowledge and skills of a knowledge worker are portable and mobile, then individuals moving from one project or responsibility to another, ought to be able to take their version of a knowledge management system with them - as laid out in the six PKMS provisions (Schmitt, 2015i).

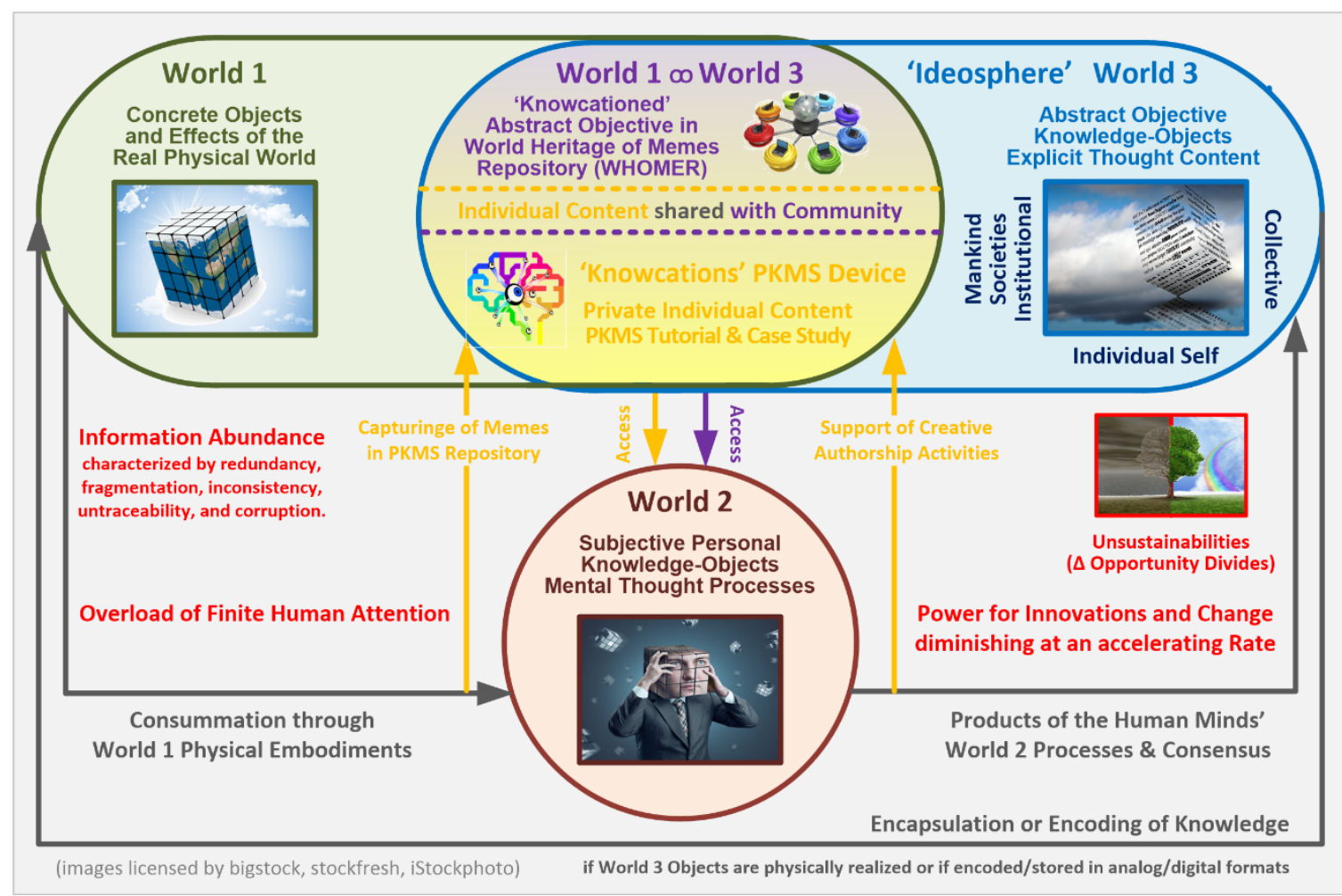

Figure 5: Popper's Three Worlds represented with the added hybrid PKMS Instantiation

The solution incorporates the functionalities of two distinctive artefacts (figure 5):

- Firstly, personal PKMS devices - named 'Knowcations' - support individual's sovereignty and autonomy by employing grass-roots, bottom-up, affordable, personal applications. They aim to put an end to the detrimental dependencies experienced as members of current providers' 'captured audiences' and signify a departure from today's top-down, heavyweight, prohibitive institutional approaches and centralized developments. Accordingly, digital personal and personalized knowledge stays always in the possession and at the personal disposal of its owner or eligible co-worker - based on standardized, consistent, transparent, flexible, secure, and non-redundant formats as well as independent of changes in one's social, educational, professional, or technological environment. 
- Secondly, a 'World Heritage of Memes Repository (WHOMER)' unlocks collaboration capabilities between the decentralized autonomous PKMS devices and voluntarily shared parts of their knowledge base capacities. Sharing one's memes and meme relationships and accessing those shared by others, facilitate the "emergence of distributed processes of collective intelligence, which in turn feed them" (Levy, 2011). Collaboratively interlinking these personal human capitals to collectively trace, harvest and utilize accumulated knowledge subsets will overall reduce redundant content and improve productivity of information seekers and suppliers alike.

Thus, nourished by the creative user conversations of many individuals' personal knowledge management, the networked 'Knowcations' and 'WHOMER' devices establish continuous feedback loops allowing the tracing, reusing, and/or repurposing of collective knowledge and ideas. The result is depicted (figure 5) as a newly configured world (w:1 $\infty \mathrm{w}: 3)$ made up of abstract objective world:3 knowledge objects after undergoing a once-off world:1-type concretization exercise in order to become a unique permanent unalterable 'WHOMER' meme resident. For updates, shared links to modified successors are integrated from PKMS devices subsequently. For further creative connections, shared links to any other meme (e.g. reference to prior works, prior or subsequent meme in writings, figures, footnotes, annotations, keywords, relevant topics, standards, relations to people or domains) are integrated likewise. Shared user activities are further supported by WHOMER's curation, knowledge, search, traceability, metrics, and educational services, all aimed to overcome the redundancy, the perishability, and potential fallibility of current online knowledge, services, and providers (Schmitt, 2015c, 2015i).

\section{PKMS as a Stream of Comprehensive Design Evaluations (G6)}

To briefly summarize: From the project's academic perspective, the author's world:2 PKMS vision - based on the analysis of the current world: 1 constraints and inadequacies - has been transformed into a world: 3 'big-T theory' and - since September 2012 - resulted in around thirty world: 1 'small-T theories' in the form of posters, conference papers, journal articles, prototype demonstrations, and tutorials. One of these publications is titled "How this paper has been created by leveraging a personal knowledge management system" (Schmitt, 2014d). However, not only this paper but all publications are captured in the $(w: 100 w: 3)$ PKMS knowledge base in order to provide a realistic 'big-T/small-T' sample set of non-redundant memes for suitable test scenarios and real-life case studies.

While some design evaluation methods - based on the meme sample sets captured - have already been applied during the iterative cycles, other are in progress or planned. This sub-section briefly refers to the methods mentioned earlier and adds further details about evaluations projected or not yet completed.

\section{Analytical Design Evaluations}

- Static Analytical Methods have been applied by positioning the PKMS features and envisioned outcomes against Gill's and Murphy's (2011) Design Task Complexity as well as the systems thinking techniques of Informing Science (Schmitt, 2015d). The envisioned impact has been looked at in the context of Kuhn's Scientific Revolutions, GeneralPurpose-Technologies (Schmitt, 2015d, 2015g), and disruptive innovations (in progress). Newly devised PKMS methods and processes have also been benchmarked against their traditional counterparts (e.g. PKMS workflow against Foraging and Sensmaking Loop, PKM4D framework vs. Pyramid of Needs, or extension of the Ignorance Matrix). 
- Dynamic Analysis Methods are in progress by comparing the metrics of the PKMS publications meme sample set with its document-centered representation as provided by Google Scholar and ResearchGate. Further 'life' demonstations are also planned (Schmitt, 2014i).

- Technical IS Architecture Analysis has been carried out on a continuous basis. It has been clear from the start that the current windows-based RDBMS environment of the prototype system in inadequate for the intended purpose. Nevertheless, setting up the logical and knowledge base structures with the imminent migration in mind has been possible. Meanwhile, a rapid development platform has been acquired and a suitable no-SQL database has been selected.

\section{Experimental Design Evaluations}

- Simulation with Artificial and Real-Life Data: The PKMS knowledge base and functionalities have been populated and tested with a variety of data sets, including, for example, the PKMS publications with their references; personal contact bases and libraries; personal chronological biographies and family trees; cocktail database; directories of journals, universities, cities, regions, and countries; 'Excellence in Research for Australia (ERA)' database sets; industrial classification systems; standards, criteria, and self-assessment for MBA accreditation.

- Controlled Experiments have been carried out by preparing and authoring new publications and presentations based on the memes and their relations captured in the PKMS knowledge base, as in case of the paper titled "How this paper has been created by leveraging a personal knowledge management system" (Schmitt, 2014d).

While a paper comparing the novel meme-based PKMS approach to current semantic and ontology-based developments is in progress, a further experiment is planned to assess the potential of the PKMS to also publish the memes and relationships in its knowledge bases in the format of formal knowledge representation languages.

\section{Testing and Observational Design Evaluations}

- Functional (Black Box) Testing has been going on continuously in line with the iterative design cycles prompted by adding functionalities and flexibilizing user interfaces and interactions. Structural (White Box) Testing has been performed - in particular - in respect to database structure modification. Having started with a complex multi-table entityrelationship-structure, the number of tables have been successively reduced by consolidating their record structures and by using self-referencing within tables now containing diverse record sets. With migration to the new rapid development platform and the no-SQL database these testing efforts have to be intensified.

- Further testing is planned in the context of a Field Study. It will take place as part of the PKMS tutorial or lecture and the students will be asked to do their assignments based on their PKMS device. Similar tests were performed some time ago with a much simpler PKMS version where students had to do their assignments about the purpose and procedures of selected business methods in the meme-based format to be subsequently shared among the cohort members.

- These field studies are planned to be incorporated in an in-depth analysis of the PKMS concept and devices in respect to their educational and organizational impact, including the typical usability and satisfaction surveys and resulting statistics leading to further empirical research reports and case studies. 


\section{Presenting Design Science Research to a Diverse Audience (G+)}

Since a PKMS embodies many entities with inherent multi-dimensional structural interdependencies, the complexity of the tasks to be handled by a user needs to be sufficiently eased by intelligible concepts and well thought-out design features. The vision communicated, meme-concept applied, functionalities offered, and tangibles provided are therefore aiming to mobilize and motivate the relevant audience and instill in them a sustainable commitment to endorse and interact with the PKMS technologies on a continuous basis in order to keep personal human capitals àjour and to reap the potential benefits.

Mostert (2013) describes Six Levels of Appreciation in the context of leadership development. However, they are equally applicable to potential PKMS users. The model starts with just appreciating the idea of the proposed system (aesthetic elegance creates curiosity), followed by recognizing a close match with one's own views (schematic resonance adds validity), and then with one's own experiences and needs (contextual relevance adds significance). At the fourth level, the added value towards one's own circumstances is realized (opportunity based on utility), followed by making it a personal priority (responsibility for advancement), with the final stage of successful implementation and utilization (enactment). However, to keep 'enacting', the added values generated for the user will have to significantly outstrip the user's perceived inconveniences due to time, effort, and self-discipline invested.

These added values have been detailed in the PKM4D framework. It builds upon the Information and Communications Technology for Development (ICT4D) notion suggested by Johri and Pal (2012) to not only focus on making effective low-cost applications available (accessibility easiness), but to enable authorship and contribution of own ideas based on one's background (expressive creativity), alone or in collaborative environments with other users/owners (relational interactivity), and with the opportunity to add productively to the world's extelligence (ecological reciprocity). The establishment of the World Heritage of Memes Repository (WHOMER) strengthens these benefits and the further eight PKM4D criteria and eases creative conversations, but also reduces inconveniences by enabling simplified access to digital extelligence shared by others.

\section{Conclusions}

By contemplating the past, present and possible futures of design thinking, Johansson-Sköldberg, Woodilla, and Çetinkaya (2013) differentiate between the professional-design oriented 'designerly thinking' and its newer simplified management-oriented 'design thinking' approach. They categorize the former into five sub-discourses with an emphasis on the creation of artefacts, on reflective practices, on problem-solving activities, on ways of reasoning and making sense of things, and on the creation of meaning. The development of the PKMS involves all five discourses and its aim is to create an artefact which, in turn, also supports all five discourses as the means for life-long-learning, resourcefulness, creative authorship and teamwork throughout an individual's academic and professional life and for his/her role as contributor and beneficiary of organizational and societal performance.

By applying the perspectives of Design Science Research, the article expands the reflections on the PKMS research paradigm further into the realm of Information Systems. Aimed foremost at a researchers' rather than a technical or managerial audience, it deals with the implementation and organizational PKMS details by referring to the dedicated prior publications and, instead, focuses on the process, relevance, rigor, evaluation, and contributions of the concept and artefact-underdevelopment. After highlighting the features of the novel approach compared to its traditional counterparts, the problem space for the system development is portrayed together with its design task complexities, followed by specifying the major PKMS research outputs. Having depicted the iterative PKMS design cycle, the problem, the rigor applied, and the contributions are presented 
in light of their relevance, and the evaluation methods employed, in progress, or projected are described.

As a result, this design science contribution pays recognition to a critical wicked problem and provides a conceptual solution with an innovative artefact (prototype-system-in-progress) that addresses it. To enhance the readability and value for managerial and technical audiences, all considerations and findings have been (for the first time) described and visualized in the context of Popper's Three Worlds. Visualizing all aspects of the PKMS concept - as evidenced in this article and all prior publications - plays a crucial role for successfully communicating the predicaments, complexities, solutions, and opportunities to a diverse portfolio of audiences.

"As academic scholars in applied fields our central mission is to develop theories that both contribute knowledge to the academic discipline (i.e. our internal stakeholders) and apply that knowledge to practice (i.e. our external stakeholders)" (attributed to Simon (O'Raghallaigh et al., 2011)). The aim of this article has been just that by attempting to follow another of Simon's observations (1969): Solving a problem simply means representing it so as to make the solution transparent.

\section{References}

Andriessen, D. (2006). On the metaphorical nature of intellectual capital: A textual analysis. Journal of Intellectual Capital, 7(1), 93-110.

Bedford, D. A. D. (2013). Knowledge management education and training in academic institutions in 2012. Journal of Information \& Knowledge Management, 12(4).

Beinhocker, E. D. (2006). The origin of wealth. Harvard Business Press.

Boisot, M. (2004). Exploring the information space: A strategic perspective on information systems. Working Paper Series WP04-003. University of Pennsylvania.

Borgman, C. L. (2007). Scholarship in the digital age. MIT Press

Bowles, J. (2014, July 17). The computerisation of European jobs - Who will win and who will lose from the impact of new technology onto old areas of employment? Bruegel, Retrieved from http://www.bruegel.org/nc/blog/detail/article/1394-the-computerisation-of-european-jobs/

Bush, V. (1945). As we may think. The Atlantic Monthly, 176(1), 101-108.

Cohen, E. (1999). Reconceptualizing information systems as a field of the transdiscipline informing science: From ugly duckling to swan. Journal of Computing and Information Technology, 7(3), 213-219.

Cohen, E. (2009). A philosophy of informing science. Informing Science: the International Journal of an Emerging Transdiscipline, 12, 1-15. Retrieved from http://inform.nu/Articles/Vol12/ISJv12p001015Cohen399.pdf

Davenport, T. H. (1994). Saving IT's soul: Human centered information management. Harvard Business Review, March-April, 72(2), 119-131.

Davies, S. (2011). Still building the Memex. Communications of the ACM, 53(2), 80-88.

Dawkins, R. (1976). The selfish gene. Paw Prints.

Distin, K. (2005). The selfish meme: A critical reassessment. Cambridge University Press.

Drori, G. S. (2010). Globalization and technology divides: Bifurcation of policy between the 'digital divide' and the 'innovation divide'. Sociological Inquiry, 80(1), 63-91.

Evans, P. C., \& Annunziata, M. (2012). Industrial Internet: Pushing the boundaries of minds and machines. General Electric.

Florida, R. (2012). The rise of the creative class - revisited. Basic Books. 
Frey, C. B., \& Osborne, M. A. (2013). The future of employment: How susceptible are jobs to computerisation? Oxford Martin.

Frost, A. (2013). Two reasons why knowledge management fails. YouTube Video. 2011. Accessed October 2, 2013 at www.youtube.com/watch?v=pF9M5ezkxQs.

Giebel, M. (2013). Digital divide, knowledge and innovations. Journal of Information, Information Technology, and Organizations 8.

Gill, T. G., \& Hevner, A. R. (2013). A fitness-utility model for design science research. ACM Transactions on Management Information Systems (TMIS), 4(2), 5.

Gill, T. G., \& Murphy, W. (2011). Task complexity and design science. In $9^{\text {th }}$ Int. Conference on Education and Information Systems, Technologies and Applications EISTA, Orlando, FL, Jul 19-22, 2011.

Grant, K. A., \& Grant, C. T. (2008). Developing a model of next generation knowledge management. Issues in Informing Science and Information Technology 5.2, 571-590.

Gratton, L. (2011). The shift - The future of work is already here. UK: HarperCollins.

Gurteen, D. (2006). Taking responsibility. Inside Knowledge, 10(1). Retrieved from http://www.ikmagazine.com/display.asp?articleid=ae03flca-f94b-4bd5-9be9-0cb68079cb6f

Heisig, P. (2014). Knowledge management - Advancements and future research needs - Results from the global knowledge research network study. Proceedings of the BAM 2014 Conference. British Academy of Management.

Hevner, A., March, S., Park, J. and Ram, S. (2004). Design science research in information systems. MIS quarterly, 28(1), 75-105.

Hilbert, M. (2011). The end justifies the definition: The manifold outlooks on the digital divide and their practical usefulness for policy-making. Telecommunications Policy 35, no. 8, pp. 715-736.

Hilbert, M. (2014). What is the content of the world's technologically mediated information and communication capacity: How much text, image, audio, and video? The Information Society, 30(2), pp. 127143.

Johansson-Sköldberg, U., Woodilla, J., \& Çetinkaya, M. (2013). Design thinking: past, present and possible futures. Creativity and Innovation Management, 22(2), 121-146.

Johri, A., \& Pal, J. (2012). Capable and convivial design (CCD): A framework for designing ICT for human development. Information Technology for Development, 18(1), 61-75.

Kahle, D. (2009). Designing open educational technology. In T. Iiyoshi \& M. S. Vijay Kumar (Eds.), Opening up education (pp. 27-46). MIT Press.

Kimura, Y. G. (2005). Kosmic alignment - A principle of global unity. Kosmos Journal. Retrieved from http://www.via-visioninaction.org/via-li/articles/Kosmic_Alignment.pdf

Koch, R. (2001). The Power Laws of Business. Nicholas Brealey.

Kuhn, T. S. (1970). The structure of scientific revolutions (2nd ed.). University of Chicago Press.

Leavitt, H. J. (1965). Applied organizational change in industry: Structural, technological and humanistic approaches. In J. G. March (Ed.) Handbook of organizations. Chicago: Rand McNally.

Levy, P. (2011). The semantic sphere 1. Wiley.

Malhotra, Y. (2004). Why knowledge management systems fail: Enablers and constraints of knowledge management in human enterprises. In Handbook on Knowledge Management 1, 577-599. Springer.

March, S. T., \& Smith, G. F. (1995). Design and natural science research on information technology. Decision support systems, 15(4), 251-266.

Mostert, M. (2013). Systemic leadership learning. Knowres Publishing.

Nonaka, I., \& Takeuchi, H. (1995). The knowledge-creating company. Oxford University Press. 
Nonaka, I., Toyama, R., \& Konno, N. (2000). SECI, Ba and leadership: A unified model of dynamic knowledge creation. Long Range Planning, 33, 5-34.

OAS. (2005). Science, technology, engineering and innovation for development: A vision for the Americas in the twenty-first century. Organization of American States. Retrieved from www.oest.oas.org/engineering/ingles/documentos/ingles_web.pdf

O’Raghallaigh, P., Sammon, D., \& Murphy, C. (2011a). The design of effective theory. Systems, Signs \& Actions, 5(1), 117-132.

O'Raghallaigh, P., Sammon, D., \& Murphy, C. (2011b). Towards an ontology of innovation models - A conceptual framework. European Conference on Information Systems 2011 Proceedings (ECIS). Paper 156.

Osis, K., \& Gaindspenkis, J. (2011). Modular personal knowledge management system and mobile technology cross-platform solution towards learning environment support. Proceedings of the Annual International Conference on Virtual and Augmented Reality in Education (VARE), 114-124.

Peffers, K., Tuunanen, T., Rothenberger, M. A., \& Chatterjee, S. (2007). A design science research methodology for information systems research. Journal of management information systems, 24(3), 45-77.

Pirolli, P. \& Card, S. (2005). The sensemaking process and leverage points for analyst technology. Proceedings of International Conference on Intelligence Analysis.

Pollard, D. (2008). PKM: A bottom-up approach to knowledge management. In T. Srikantaiah, \& M. Koenig (Eds), Knowledge management in practice: Connections and context (95-109). Information Today.

Popper, K. (1959). The Logic of Scientific Discovery. New York, NY., USA: Basic Books.

Popper, K. (1972) Objective knowledge - An evolutionary approach. Oxford University Press.

Popper, K. (1978) Three worlds - The Tanner lecture on human values delivered. The University of Michigan April 7, 1978.

Probst, G. (1998). Practical knowledge management - A model that works. Prism. Second Quarter, Arthur D. Little, 17-29.

Rylander, A. (2009). Design thinking as knowledge work: Epistemological foundations and practical implications. Design Management Journal, 4(1), 7-19.

Sandberg, A. (2000). Memetics. Retrieved from http://www.aleph.se/Trans/Cultural/Memetics/

Sarka, P., Caldwell, N. H. M., Ipsen, C., Maier, A. M., \& Heisig, P. (2014). Future research in technological enablers for knowledge management: A worldwide expert study. In British Academy of Management Conference Proceedings, September, pp. 9-11.

Schmitt, U. (2012). Knowcations - The quest for a personal knowledge management solution. $12^{\text {th }}$ International Conference on Knowledge Management and Knowledge Technologies (i-Know), Sep 05-07 2012, Graz, Austria. Copyright 2012 ACM 978-1-4503-1242-4/12/09. Graz: ACM. Retrieved from http://dl.acm.org/citation.cfm?id=2362469 or http://www.researchgate.net/publication/254464094

Schmitt (2013a). Making personal knowledge management part and parcel of higher education programme and services portfolios. Paper presented at the $6^{\text {th }}$ World Universities Forum. Jan 10-11, 2013, Vancouver, Canada. (published in Schmitt, U., \& Butchart, B. A. H. (2014)).

Schmitt, U. (2013b). Knowcations - A meme-based personal knowledge management system-in-progress. $8^{\text {th }}$ International Conference on e-Learning (ICEL), ACPI, Jun 27-28, 2013, Cape Town, South Africa. Retrieved from http://dx.doi.org/10.13140/2.1.2773.4725 (paper) http://dx.doi.org/10.13140/2.1.2016.2880 (poster)

Schmitt, U. (2013c). Innovating personal knowledge creation and exploitation. $2^{\text {nd }}$ Global Innovation and Knowledge Academy (GIKA), Jul 9-11, 2013, Valencia, Spain. Retrieved from http://dx.doi.org/10.13140/2.1.3717.6003 
Schmitt, U. (2013d, July). Managing personal knowledge for the creative class economy. Poster presented at WorldFuture 2013 - Exploring the Next Horizon, Jul 19-21, 2013, Chicago, U.S.A. Retrieved from http://dx.doi.org/10.13140/2.1.1495.5201

Schmitt, U. (2013e). Managing personal knowledge to make a difference. $27^{\text {th }}$ British Academy of Management Conference (BAM), Sep 10-12, 2013, Liverpool, United Kingdom. Retrieved from http://dx.doi.org/10.13140/2.1.1227.2328

Schmitt, U. (2013f). Furnishing knowledge workers with the career tools they so badly need. International HR Development Conference (HRDC), Oct 17-18, 2013, Mauritius. Retrieved from http://dx.doi.org/10.13140/2.1.1718.7526

Schmitt, U. (2013g). Knowcations - Conceptualizing a personal second generation knowledge management system. In A. M. J. Skulimowski (Ed), Looking into the future of creativity and decision support systems. Proceedings of the $8^{\text {th }}$ Conference on Knowledge, Information and Creativity Support Systems KICSS, Nov 07-09, 2013, Krakow, Poland. Retrieved from http://dx.doi.org/10.13140/2.1.1208.8008 (for extend version, see Schmitt, 2016c).

Schmitt, U. (2014a, January). Leveraging personal knowledge management systems for business and development. Paper presented at the $2^{\text {nd }}$ Conference Africa Academy of Management (AFAM), Jan 9-11, 2014, Gaborone, Botswana. Retrieved from http://www.researchgate.net/publication/268741050

Schmitt, U. (2014b). Personal knowledge management devices - The next co-evolutionary driver of human development?! International Conference on Education and Social Sciences (INTCESS14), Feb 03-05, 2014, Istanbul, Turkey. Retrieved from http://dx.doi.org/10.13140/2.1.4035.0401

Schmitt, U. (2014c). The role of personal knowledge management systems in making citizens highly knowledgeable. $8^{\text {th }}$ International Technology, Education and Development Conference (INTED), Mar 10-12, 2014, Valencia, Spain. Retrieved from http://dx.doi.org/10.13140/2.1.2492.7049

Schmitt, U. (2014d). How this paper has been created by leveraging a personal knowledge management system. $8^{\text {th }}$ International Conference on Higher Education (ICHE), Mar 16-18, 2014, Tel Aviv, Israel. Retrieved from http://dx.doi.org/10.13140/2.1.4379.1049

Schmitt, U. (2014e). From circuits of knowledge to circuits of personal knowledge management concepts. Paper presented at the Conference on Organizational Learning, Knowledge and Capabilities (OLKC). Apr 22-24, 2014. Oslo, Norway. Retrieved from http://dx.doi.org/10.13140/2.1.3527.1360

Schmitt, U. (2014f). Overcoming the seven barriers to innovating personal knowledge management systems. International Forum on Knowledge Asset Dynamics (IFKAD), Jun 11-13, 2014, Matera, Italy. Retrieved from http://dx.doi.org/10.13140/2.1.3789.2800

Schmitt, U. (2014g) see Schmitt, U., \& Butchart, B. A. H. (2014).

Schmitt, U. (2014h). Proposing a next generation of knowledge management systems for creative collaborations in support of individuals and institutions. Proceedings of the $6^{\text {th }}$ International Joint Conference on Knowledge Discovery, Knowledge Engineering and Knowledge Management (IC3K), Oct 21-24, 2014, Rome, Italy pp. 346-353. 978-989-758-050-5. Retrieved from http://www.researchgate.net/publication/268741643

Schmitt, U. (2014i). Concept and prototype of a 'next generation' personal knowledge management system. Prototype Demonstration at the $6^{\text {th }}$ International Joint Conference on Knowledge Discovery, Knowledge Engineering and Knowledge Management (IC3K), Oct 21-24, 2014, Rome, Italy.

Schmitt, U. (2014j). Supporting digital scholarship and individual curation based on a meme-and-cloudbased personal knowledge management concept. Presentation at the Conference of the International Journal of Arts and Sciences (IJAS), Oct 28-31, 2014, Rome, Italy. (Article published (2015e)). Retrieved from http://www.researchgate.net/publication/268741922

Schmitt, U. (2014k). Making sense of e-skills at the dawn of a new personal knowledge management paradigm. Proceedings of the e-Skills for Knowledge Production and Innovation Conference, November 17-21, 2014, Cape Town, South Africa, pp. 417-447. ISSN 2375-0634. Retrieved from 
http://dx.doi.org/10.13140/2.1.4932.6409 (abstract) or http://dx.doi.org/10.13140/2.1.4267.0404 (poster) or http://proceedings.e-skillsconference.org/2014/e-skills417-447Schmitt815.pdf (paper)

Schmitt, U. (20141). Significance of memes for the successful formation of autonomous personal knowledge management systems. Proceedings of the $9^{\text {th }}$ International Conference on Knowledge, Information and Creativity Support Systems (KICSS), Nov 06-08, 2014, Limassol, Cyprus, pp. 339-345. 978-9963-700-84-4. Retrieved from http://dx.doi.org/10.13140/2.1.5135.6485 (for extend version, see Schmitt, 2016a).

Schmitt, U. (2014m). The significance of 'ba' for the successful formation of autonomous personal knowledge management systems. Proceedings of the $9^{\text {th }}$ International Conference on Knowledge, Information and Creativity Support Systems (KICSS), Nov 06-08, 2014, Limassol, Cyprus, pp. 327-338. 978-9963-700-84-4. Retrieved from http://dx.doi.org/10.13140/2.1.1432.8649 (for extend version, see Schmitt, 2016b).

Schmitt, U. (2014n). Who needs personal knowledge management anyway and what for? Poster Presentation at the e-Skills for Knowledge Production and Innovation Conference, Cape Town, South Africa, 17-21 November 2014. Retrieved from http://www.researchgate.net/publication/271199225

Schmitt, U. (2015a). From ICT4D to PKM4D: Tackling opportunity divides with a 'new knowledge management generation' of decentralized personal devices. Paper presented at the $11^{\text {th }}$ International Conference on Environmental, Cultural, Economic, \& Social Sustainability, Jan 21-23, 2015, Copenhagen, Denmark. Retrieved from http://www.researchgate.net/publication/270881065

Schmitt, U. (2015b). Embracing corporate knowledge assets via autonomous personal knowledge management devices. Paper presented at the $15^{\text {th }}$ International Conference on Knowledge, Culture, and Change in Organizations, Feb 19-20, 2015, Berkeley, California, USA. (Published in (2016d)). Retrieved from http://www.researchgate.net/publication/273064407

Schmitt, U. (2015c). Creating and tracing knowledge assets based on creative conversations of autonomous personal knowledge management devices and shared 'world heritage site of memes' repositories. Paper presented at the $11^{\text {th }}$ International Conference on Technology, Knowledge, and Society, Feb 23-24, 2015, Berkeley, California, USA. (Published in (2015i)). Retrieved from http://www.researchgate.net/publication/272396928

Schmitt, U. (2015d). Putting personal knowledge management under the macroscope of informing science. International Journal of an Emerging Transdiscipline (InformingSciJ) 2015, Vol. 18: 145-175. 15214672. Retrieved from http://www.inform.nu/Articles/Vol18/ISJv18p145-175Schmitt1634.pdf

Schmitt, U. (2015e). Supporting digital scholarship and individual curation based on a meme-and-cloudbased personal knowledge management concept. Academic Journal of Science (AJS), Vol. 4/1, pp. 220-237, 2165-6282. Retrieved from http://www.universitypublications.net/ajs/0401/pdf/R4ME489.pdf

Schmitt, U. (2015f). Quo Vadis, knowledge management: A regeneration or a revolution in the making? Journal of Information \& Knowledge Management (JIKM), Vol. 14, No. 4. Retrieved from http://dx.doi.org/10.1142/S0219649215500306

Schmitt, U. (2015g). Knowledge management as artefact and expediter of interdisciplinary discourses. Proceedings of $9^{\text {th }}$ International Multi-Conference on Society, Cybernetics and Informatics (IMSCI), Orlando, USA, July 12-15, 2015. 978-1-941-763-26-1, pp. 92-98. Retrieved from http://www.researchgate.net/publication/276057497

Schmitt, U. (2015h). Knowledge management systems as an interdisciplinary communication and personalized general-purpose technology. In Special Issue of the Journal of Systemics, Cybernetics and Informatics 2015: Invited Papers of the Plenary Keynote Speakers at the IMS 2015 Conferences $\left(9^{\text {th }}\right.$ International Multi-Conference on Society, Cybernetics and Informatics (IMSCI), Orlando, Florida, USA, 12-15 July 2015). 1690-4524. Retrieved from http://www.researchgate.net/publication/278784977

Schmitt, U. (2015i). Towards a 'world heritage of memes repository' for tracing ideas, tailoring knowledge assets and tackling opportunity divides: Supporting a novel personal knowledge management concept. 
The International Journal of Technology, Knowledge \& Society: Annual Review, Vol. 10, pp. 25-44, 1832-3669. Retrieved from http://www.researchgate.net/publication/277469690

Schmitt, U. (2015j). The design thinking approach taken for developing a novel personal knowledge management concept and prototype system. Paper presented at the Emerging Technologies \& Authentic Learning within Higher Vocational Education Conference 2015, Cape Town, South Africa, Aug 31 Sep 2, 2015 (integrated in this article). Retrieved from http://www.researchgate.net/publication/277776234

Schmitt, U. (2015k). The promise of autonomous personal knowledge management devices to be a key educational technology for growing a $21^{\text {st }}$ century knowledge society. Paper presented at the Emerging Technologies \& Authentic Learning within Higher Vocational Education Conference 2015, Cape Town, South Africa, Aug 31 - Sep 2, 2015. Retrieved from http://www.researchgate.net/publication/277776326

Schmitt, U. (2016a). The significance of memes for the successful formation of autonomous personal knowledge management systems. In: Kunifuji, S., Papadopoulos, G. A., Skulimowski, A. M. J. (Eds.) Knowledge, Information and Creativity Support Systems (Selected [extended] Papers from KICSS'2014, $9^{\text {th }}$ International Conference held in Limassol, Cyprus, on November 6-8, 2014), Springer Series: Advances in Systems and Computing (AISC), Vol. 416, pp. 391-407. http://www.researchgate.net/publication/278027220

Schmitt, U. (2016b). The significance of 'ba' for the successful formation of autonomous personal knowledge management systems. In: Kunifuji, S., Papadopoulos, G. A., Skulimowski, A. M. J. (Eds.) Knowledge, Information and Creativity Support Systems (Selected [extended] Papers from KICSS'2014, $9^{\text {th }}$ International Conference held in Limassol, Cyprus, on November 6-8, 2014), Springer Series: Advances in Systems and Computing (AISC), Vol. 416, pp. 409-419. http://www.researchgate.net/publication/278027532

Schmitt, U. (2016c). Knowcations - Positioning a meme and cloud-based $2^{\text {nd }}$ generation personal knowledge management system. In A. M. J. Skulimowski and J. Kacprzyk (Eds), Knowledge, Information and Creativity Support Systems: Recent Trends, Advances and Solutions (Selected Papers from KICSS'2013 $-8^{\text {th }}$ International Conference on Knowledge, Information, and Creativity Support Systems, Nov 7-9, 2013, Kraków, Poland), Springer Series: Advances in Intelligent Systems and Computing (AISC), Vol.364, pp. 243-257. http://www.researchgate.net/publication/273143388.

Schmitt, U. (2016d). Tools for exploration and exploitation capability: Towards a co-evolution of organizational and personal knowledge management systems. The International Journal of Knowledge, Culture, and Change Management: Annual Review, Volume 15, pp. 23-47. http://www.researchgate.net/publication/282852429

Schmitt, U. (2016e). "Design Science Research Championing Personal Knowledge Management System Development." Proceedings of the Informing Science + IT Education Conferences, Vilnius, Lithuania, June 27 -July 1. (this paper)

Schmitt, U. (2016f). Redefining Knowledge Management Education with the Support of Personal Knowledge Management Devices. Accepted Paper at the $3{ }^{\text {rd }}$ International KES Conference on Smart Education and e-Learning (KES-SEEL-16), June 15-17, 2016, Tenerife, Spain, to be published in Springer's KES Smart Innovation Systems and Technologies Series. http://www.researchgate.net/publication/292963777

Schmitt, U. (2016g). Utilizing the Disruptive Promises of PKM Devices for Strengthening Organizational Capabilities of Innovativeness and Leadership (2016g). Accepted Paper at the 5th Ashridge International Research Conference (AIRC5), Jul 3-5, 2016, Berkhamsted, UK. http://www.researchgate.net/publication/298305402

Schmitt, U., \& Butchart, B. A. H. (2014). Making personal knowledge management part and parcel of higher education programme and services portfolios. Journal of the World Universities Forum, 6(4). Retrieved from http://wuj.cgpublisher.com/product/pub.173/prod.392 or http://www.researchgate.net/publication/268686737 
Schütt, P. (2003). The post-Nonaka knowledge management. J. UCS 9(6): 451-462.

Short, J. E., Bohn, R. E., and Baru, C. (2011). How much information? 2010 report on enterprise server information. UCSD Global Information Industry Center.

Simon, H. A. (1967). The business school - A problem in organizational design. Journal of Management Studies 4(1): 1-16.

Simon, H. (1969). The science of the artificial. Cambridge, MA: MIT Press

Simon, H. A. (1971). Designing organizations for an information-rich world. In M. Greenberger (Ed.), Computers, communication, and the public interest. Baltimore: Johns Hopkins Press.

Stanford (2015) d.school bootcamp bootleg. Institute of Design at Stanford. Retrieved June 22, 2015, from http://dschool.stanford.edu/wp-content/uploads/2013/10/METHODCARDS-v3-slim.pdf

Stewart, I. \& Cohen, J. (1999). Figments of reality - The evolution of the curious mind. Cambridge University Press.

United States District Court - Southern District of New York. (2013). The Authors Guild Inc. against Google Inc., Case 1:05-cv-08136-DC, Document 1088, Filed 11/14/13. Retrieved from www.wired.com/images blogs/threatlevel/2013/11/chindecision.pdf

Van Kleek, M., \& O’Hara, K. (2014). The future of social is personal: The potential of the personal data store. In D. Miorandi, V. Maltese, M. Rovatsos, A. Nijholt \& J. Stewart (Eds.), Social collective intelligence: Combining the powers of humans and machines to build a smarter society (pp. 125-158). Springer. Retrieved from http://eprints.soton.ac.uk/363518/1/pds.pdf

Wierzbicki, A. P. \& Nakamori, Y. (2006). Creative space: Models of creative processes for the knowledge civilization age. Springer Publishing Company.

Wierzbicki, A. P. \& Nakamori, Y. (2007). Creative environments: Issues of creativity support for the knowledge civilization age. Springer Publishing Company.

Wiig, K. M. (2011). The importance of personal knowledge management in the knowledge society. In D. J. Pauleen, \& G. E. Gorman (Eds), Personal knowledge management (pp. 229-262). Gower.

Wilson, T. D. (2002). The nonsense of "knowledge management". Information Research 8(1).

World Bank Institute. (2008). Knowledge for Development (K4D), The World Bank Institute's program on building knowledge economies. WBI. DOI= http://go.worldbank.org/AW9KZWJB10

\section{Biography}

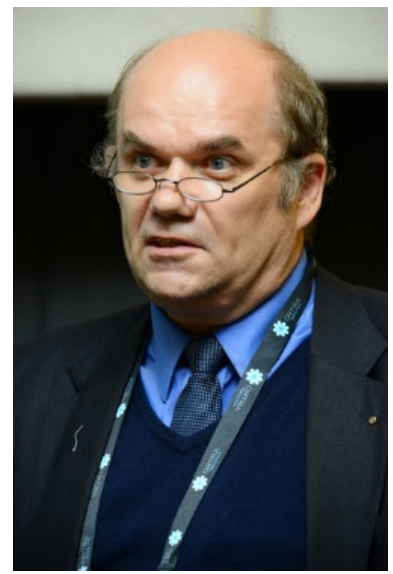

Ulrich Schmitt's professional background covers positions as IT and management consultant in London and Basle, as professor and vice president at two independent universities in Germany, as well as Vice Rector at the Polytechnic of Namibia and Dean of the Graduate School at the University of Botswana. He studied Management and Industrial Engineering at TU Berlin and Cranfield University, completed his PhD at Basle University, and a Science and Research Management Program at Speyer University. Currently, he is focussing on Personal Knowledge Management and is Professor Extraordinaire at the University of Stellenbosch Business School.

See web site for previous and upcoming PKM related work:

http://pkm.knowcations.net/publications

http://www.researchgate.net/profile/Ulrich_Schmitt2 